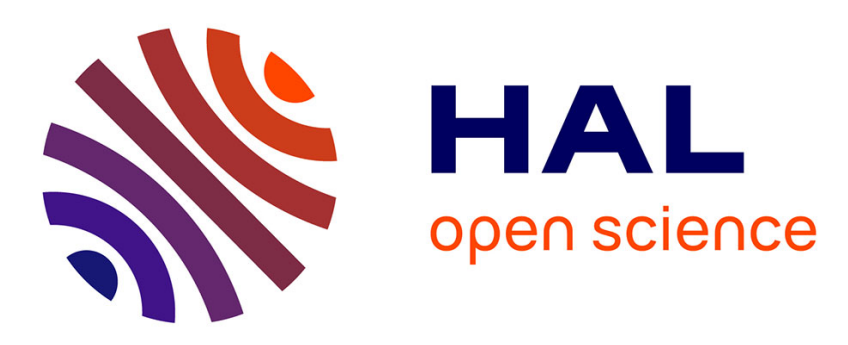

\title{
Pharmacokinetics of natural mistletoe lectins after subcutaneous injection
}

\author{
Roman Huber, Jürgen Eisenbraun, Barbara Miletzki, Michael Adler, Rainer \\ Scheer, Reinhild Klein, Christoph H. Gleiter
}

\section{- To cite this version:}

Roman Huber, Jürgen Eisenbraun, Barbara Miletzki, Michael Adler, Rainer Scheer, et al.. Pharmacokinetics of natural mistletoe lectins after subcutaneous injection. European Journal of Clinical Pharmacology, 2010, 66 (9), pp.889-897. 10.1007/s00228-010-0830-5 . hal-00593327

\section{HAL Id: hal-00593327 \\ https://hal.science/hal-00593327}

Submitted on 14 May 2011

HAL is a multi-disciplinary open access archive for the deposit and dissemination of scientific research documents, whether they are published or not. The documents may come from teaching and research institutions in France or abroad, or from public or private research centers.
L'archive ouverte pluridisciplinaire HAL, est destinée au dépôt et à la diffusion de documents scientifiques de niveau recherche, publiés ou non, émanant des établissements d'enseignement et de recherche français ou étrangers, des laboratoires publics ou privés. 




\section{Pharmacokinetics of natural mistletoe lectins after subcutaneous injection}

\begin{tabular}{|c|c|}
\hline Journal: & European Journal of Clinical Pharmacology \\
\hline Manuscript ID: & EJCP-2009-0404.R1 \\
\hline Type of submission: & Original \\
\hline $\begin{array}{r}\text { Date Submitted by the } \\
\text { Author: }\end{array}$ & 13-Apr-2010 \\
\hline Complete List of Authors: & $\begin{array}{l}\text { Huber, Roman; University Hospital Freiburg, Environmental Health } \\
\text { Sciences } \\
\text { Eisenbraun, Jürgen; Abnoba GmbH, Abnoba GmbH } \\
\text { Miletzki, Barbara; CenTrial, CenTrial } \\
\text { Adler, Michael; Chimera Biotec GmbH, Chimera Biotec GmbH } \\
\text { Scheer, Rainer; Abnoba GmbH, Abnoba GmbH } \\
\text { Klein, Reinhild; Department of Internal Medicine II, University of } \\
\text { Tübingen } \\
\text { Gleiter, Christoph; CenTrial, CenTrial }\end{array}$ \\
\hline
\end{tabular}

\section{scholarONE"


Pharmacokinetics of natural mistletoe lectins after subcutaneous injection

Roman Huber ${ }^{1}$, Jürgen Eisenbraun ${ }^{2}$, Barbara Miletzki ${ }^{3}$, Michael Adler ${ }^{4}$, Rainer Scheer ${ }^{2}$, Reinhild Klein ${ }^{5}$, Christoph H. Gleiter ${ }^{3}$

${ }^{1}$ Department of Environmental Health Sciences, University Hospital Freiburg, Germany

${ }^{2}$ Abnoba GmbH, Pforzheim, Germany

${ }^{3}$ CenTrial GmbH, Tübingen/Ulm, Germany

${ }^{4}$ Chimera Biotec $\mathrm{GmbH}$, Dortmund, Germany

${ }^{5}$ Department of Internal Medicine II, University of Tübingen, Germany

Corresponding author

Dr. Roman Huber

Department of Environmental Health Sciences

University Hospital Freiburg

Breisacher Str. 115b

D-79106 Freiburg

Germany

Phone: 00497612708201

Fax: 00497612708323

Email: roman.huber@uniklinik-freiburg.de 
Purpose: Knowledge of natural mistletoe lectins (nML) pharmacokinetics can be regarded as essential for further rational studies with mistletoe preparations. Studies with intravenous application of a recombinant type II ribosome inactivating protein $\underline{(\mathrm{rML})}$ analogous to $\underline{\mathrm{n} M L}$ revealed a short half life of about 13 minutes in cancer patients. This open-label, phase I, monocenter clinical trial was performed in order to describe the pharmacokinetics of nML. Methods: In 15 healthy male volunteers aged 18-42 years $\underline{n} M L$ were detected with a modified sandwich Immuno-PCR technique (Imperacer®, Chimera Biotec) after single subcutaneous injection of a mistletoe extract (abnobaVISCUM ${ }^{\circledR}$ Fraxini 20mg) with marketing authorisation, containing about $20 \mu \mathrm{g} n \mathrm{nML}$ per millilitre. Secondary objectives were safety and the number of activated natural killer cells (CD54+/CD94+)._Results: In none of the volunteers $\underline{n} \mathrm{ML}$ were detectable before the injection and in all volunteers $\underline{n}$ ML were detected in serum samples after the injection. Individual variability however was large. The mean and median peak concentration was reached 1 and 2 hours after injection, respectively. In some of the volunteers nML were still detectable at the final investigation 2 weeks after injection. The injection resulted in fever and flue like symptoms in all volunteers but no serious adverse events occurred. All symptoms and local reactions at the injection site completely disappeared within a range of 4 to 95 days. The number of activated natural killer cells did not change. Conclusions: $n$ ML from abnobaVISCUM ${ }^{\circledR}$ Fraxini $20 \mathrm{mg}$ are detectable in serum after a single subcutaneous injection. Detectability is considerably longer compared to intravenous. $\underline{\mathrm{rML}}$. The subcutaneous injection of this preparation without usual pretreatment with lower doses results in short-lasting fever and other flu-like symptoms.

\section{Key words:} abnobaVISCUM, anthroposophical medicine, healthy volunteers, phytotherapy, safety, NKcells 
Introduction

Mistletoe preparations are used since decades for supportive cancer treatment within the concept of anthroposophical medicine. Despite more than 40 randomized clinical trials, the efficacy of mistletoe treatment in cancer therapy is yet not clear and discussed controversially [1]. Reasons for this unsatisfactory situation are, that different mistletoe preparations with different ingredients in different concentrations have been tested and that the pharmacology of mistletoe extracts is unclear. Active ingredients of mistletoe extracts are mainly mistletoe lectins (믄), viscotoxins and polysaccharides. From these, nㅡㄴ are the most interesting substances for anticancer activity. They have in in-vitro and animal models been demonstrated to have distinct cytotoxic properties $[2,3]$. In doses below cytotoxicity nML stimulate the unspecific and specific immune system in humans [4].

ML are glycoproteins and occur naturally in 2 types, the ribosome inactivating proteins of class 2, which are devided in the 3 subtypes nML-I, -II and -III and viscum album chitinbinding ML (cbML). The molecular weight of nML I-III is about $63 \mathrm{kDa}$. They have very similar biological properties and are composed of a $\mathrm{N}$-glycosidase (A-chain) and a galactoside-recognizing lectin (B-chain), connected by a disulfide bridge $[5,6]$. The A-chain inhibits protein synthesis $[7,8]$. The B-chain binds to carbohydrate residues on the cell surface, thus entering the cell by receptor-mediated endocytosis and inducing apoptosis of the cell $[8,9]$. The cbML belongs to a different class of lectins with a different structure, low antigenicity and a molecular weight of only about $11 \mathrm{kDa}$ [10]. It is far less toxic than nML IIII and is not included in our analysis.

Recently, the technique to detect $\underline{\underline{n} M L} \underline{\mathrm{I}-\mathrm{III}}$ in nanogram ranges in human serum has been developed [1미 12]. A recombinant type II ribosome inactivating protein (rML) analogous to natural mistletoe lectin I revealed a short half life of about 13 minutes in cancer patients [12]. Knowledge of $\underline{n} \mathrm{ML}$ pharmacokinetics can be regarded as important to optimize clinical use and further rational studies with mistletoe preparations. To the first time, we therefore investigated the pharmacokinetics of natural mistletoe lectin from a commercially available mistletoe preparation in humans. 
Patients and Methods

The study was performed as an uncontrolled, non-randomized, open-label, phase I, monocenter clinical trial. Primary outcome was the pharmacokinetics of $\underline{n} M L$ following a single dose $(1 \mathrm{ml})$ of subcutaneously administered abnobaVISCUM ${ }^{\circledR}$ Fraxini $20 \mathrm{mg}$ in healthy male volunteers. Secondary outcomes were safety and activation markers (CD54+/CD94+) on natural killer (NK) cells. This marker was selected, because treatment of patients with metastatic colorectal cancer and lung cancer with NK-cells (CD54+/CD94+) activated by heat shock proteins showed promising anti-tumor effects [1]ㅡ. We wanted to test the hypothesis, that mistletoe-induced fever activates NK-cells.

The study comprised a screening (examination 1), a period of hospitalisation (examination 2 to 6) from the night before until 72 hours after s.c. injection of the IMP (investigational medicinal product) and a final follow-up (examination 7) on day $14+/-3$ after injection of the IMP. nML-concentrations in volunteers' sera were analysed before and 0.3, 0.7, 1.0, 1.5, 2, 3, $4,5,6,8,10,12,18,24,36,48,72$ and 336 hours after injection of the IMP. Safety laboratory parameters (creatinine, urea, uric acid, sodium, potassium, chloride, calcium, creatine kinase, alanin amino transferase (ALT), aspartate amino transferase (AST), lactate dehydrogenase, alkaline phosphatase, gamma-glutamyl-transferase, total bilirubin, total protein, albumin, alpha-amylase, C-reactive protein (CRP), cholesterol, triglycerides, glucose) were determined at examinations 1, 2, and 7. CD54+/CD94+ NK cells were determined before and 6, 24 and 72 hours after injection of the IMP.

Inclusion criteria were: 18-45 years old non smoking healthy males, body mass index 18.5-28 $\mathrm{kg} / \mathrm{m}^{2}$ with normal values for blood pressure, pulse rate, body temperature, normal haematological, biochemical and coagulation parameters and normal electrocardiogram. Exclusion criteria were signs of any clinically significant disease, regular use of medication, drug abuse, positive urine screening for drugs, positive blood test for ethanol, participation in another clinical trial, previous therapy with mistletoe preparations, history of allergy to a medicinal product, allergic diseases except the investigator considered them as clinically irrelevant for the purpose of this clinical trial, positive HIV, hepatitis B or C serology, regular intake of more than $20 \mathrm{~g}$ ethanol per day, donation of blood within 3 months prior to study entry, difficult peripheral venous access and inability to understand the nature and the extent of the trial. 
1

2

3

4

5

6

7

8

9

10

11

12

13

14

Only volunteers who gave written informed consent and met all eligibility criteria were included into the study.

The relevant ethics committee had provided a favourable opinion on the clinical trial prior to study start and the study was performed in compliance with the principles of Good Clinical Practice and the Declaration of Helsinki.

\section{Medication}

AbnobaVISCUM $^{\circledR}$ Fraxini 20mg is an injectable, endotoxin free plant extract from the European mistletoe species Viscum album L. for the treatment of malignant tumors, tumor recurrences and defined precanceroses. As abnobaVISCUM ${ }^{\circledR}$ Fraxini $20 \mathrm{mg}$ has the highest content of $\underline{\mathrm{n} M L}$ (approx. 20.000ng/ml) of all commercially available mistletoe preparations, this preparation was chosen in order to detect $\underline{n} \mathrm{ML}$ in the nanogram range after subcutaneous injection. Mistletoes from deciduous trees like the ash tree, from which abnobaVISCUM ${ }^{\circledR}$ Fraxini is derived, have relatively high proportions of nML I in relation to nML II/III [14] but due to methodological difficulties, no differentiation of the MLs could be performed in the commercial extract. The amount of cbML in abnobaVISCUM ${ }^{\circledR}$ Fraxini $20 \mathrm{mg}$ has been about $1 \mu \mathrm{g} / \mathrm{ml}[15]$. Each volunteer was given the same single dose $(1 \mathrm{ml})$ of subcutaneously administered abnobaVISCUM ${ }^{\circledR}$ Fraxini 20mg. No dose adjustments were necessary, since the inclusion criteria limited the body mass index of the volunteers to a range of $18.5-28 \mathrm{~kg} / \mathrm{m}^{2}$. Intratumoral injections with abnobaVISCUM ${ }^{\circledR}$ Fraxini $20 \mathrm{mg}$ resulted in highly significant tumor reductions in human pancreatic cancer xenografts [3].

Quantification of $\underline{n}$ ML and activated NK-cells

Each blood sample was put on ice immediately after collection and centrifuged for 10 minutes at $4{ }^{\circ} \mathrm{C}$ and $2500 x g$. Thereafter, at least $2 \mathrm{ml}$ of serum were immediately frozen and stored at $-80^{\circ} \mathrm{C}$ in the clinical trial center. 
nML in the sera of the volunteers was measured by an ultrasensitive immuno-PCR method $\left(\right.$ Imperacer $\left.^{\circledR}\right)[1 \underline{1}, 1 \underline{2}, 1 \underline{6}]$, which combines protein detection through ELISA with the exponential signal amplification typical for PCR. The method was validated by Chimera Biotech GmbH, Dortmund, Germany for natural mistletoe lectins of abnobaVISCUM ${ }^{\circledR}$ in human serum. It does not discriminate between the nML subtypes I-III. Due to the completely different structure it does not detect cbML. Briefly, the antigen was immobilized on captureantibody coated microplate surfaces directly from the serum samples as delivered for analysis without additional purification. For minimization of background effects, the samples were diluted 1:3 in a detergent-containing sample dilution buffer. Parallel to the samples, a dilution series of the antigen was studied, abnobaVISCUM ${ }^{\circledR}$ Fraxini $20 \mathrm{mg}$, batch no. $407 \mathrm{~B} 04$ and abnobaVISCUM $^{\circledR}$ Mali 20 mg, batch no. $502 B 33$ (both ABNOBA GmbH, Germany) were used as reference substance. Spiked samples were used as a calibration curve for quantification of the antigen and testing robustness and specifity. Each calibration curve $(6000-93.75 \mathrm{pg} / \mathrm{ml}$ antigen) was prepared in antigen-free individual serum, taken previous to the application of the antigen. This dilution series was additionally frozen to simulate the effect of freezing on the antigen-containing samples for analysis. Following incubation of the samples and the calibration curve, the immobilized antigen was coupled with a specific antibody-DNA conjugate. The assay was carried out with a lectin-specific tailored Imperacer ${ }^{\circledR}$ Kit (No. 11-030, Chimera Biotec, Germany). Monoclonal mouse-anti-ML antibody 5F5, antiML-I-(A-Chain) and 5H8 Anti-ML-A (Institut für Immunopräparate und Nährmedien GmbH, , Germany) were used as detection- and capture antibody, respectively.

After a washing step the DNA-marker was amplified by real-time PCR. In data analysis, a baseline correction was applied. The instrument software calculates the threshold cycle $(\mathrm{Ct})$, which represents the first PCR cycle at which the reporter signal exceeds the signal of the baseline ("threshold"), and sets it in the phase where the signal increases linearly. Baseline correction and threshold were identical in all validation measurements. $\Delta \mathrm{Ct}$ values were calculated by subtracting the $\mathrm{Ct}$ values obtained for each signal from the total number of cycles carried out in the experiment. This purely mathematical conversion facilitates the comparison of the data with conventional ELISA data as $\Delta \mathrm{Ct}$ values are directly proportional to the antigen concentration. 
Assay precision, sensitivity, specificity and robustness were suitable for this pharmacokinetic study. A linear concentration range of the Imperacer $^{\circledR}$ assay was validated from 0.1-100 ng nML/ml. Regarding a dose of $20.000 \mathrm{ng} n \mathrm{nML}$ and approximately $3000 \mathrm{ml}$ serum in humans a maximum concentration of $6.6 \mathrm{ng} \mathrm{nML} / \mathrm{ml}$ was expected to be measured, if $100 \%$ of injected nML would have been distributed equally and immediately in the blood circulation without metabolisation. With a linear measurement range starting at $0.1 \mathrm{ng}$ it was possible to measure a quantitative $\mathrm{nML}$ concentration if only $5 \%$ of the injected amount of $1 \mathrm{ml}$ abnobaVISCUM ${ }^{\circledR}$ Fraxini $20 \mathrm{mg}$ appeared in the blood circulation at one sample timepoint. This was expected to be low enough for a successful detection of the kinetic parameters. 0.1 $\mathrm{ng} \underline{n} \mathrm{ML} / \mathrm{ml}$ was the cut off value, from which on $\underline{n} M L$ concentrations were positive.

For the determination of NK cells, heparinized blood was used, and peripheral blood mononuclear cells (PBMC) were isolated by Ficoll-gradient. After staining with PEconjugated anti-CD56, PerCP-conjugated anti-CD45 and FITC conjugated anti-CD94 antibodies (all obtained from Becton-Dickinson [San Jose, CA]) the PBMC were incubated with the respective antibodies or IgG isotype control antibodies (BD Biosciences Pharmingen). A minimum of 10000 lymphocytes were counted. Quadrants were set based upon the isotype controls for each antibody.

\section{Statistics}

No comparison with a control group was planned and no data for comparison did exist. Since the study was to be conducted for exploratory purposes no statistically based sample size calculation was performed. It was planned to include $n=16$ (two groups of $n=8$ ) healthy male volunteers into the trial, because this is a sufficient number to enable evaluation of the single dose-pharmacokinetics of abnobaVISCUM ${ }^{\circledR}$ Fraxini $20 \mathrm{mg}$.

For statistical analyses two populations of clinical trial participants were defined:

1) The pharmacokinetic population which had to include all clinical trial participants who provided evaluable and interpretable pharmacokinetic results during the $72 \mathrm{hrs}$ after dosing of abnobaVISCUM $^{\circledR}$ Fraxini 20mg.

2) The safety population which had to encompass all clinical trial participants who met all eligibility criteria and were included in the clinical trial. 
The analyses of the nML-pharmacokinetics and the immunological activation marker had to be performed on the pharmacokinetic population. The evaluation of safety and tolerability had to be performed on the safety population. Missing or manipulated data had to be corrected if possible. If this was not possible the data were to be treated as missing data.

Results

$\mathrm{N}=35$ volunteers were screened and $\mathrm{n}=20$ were found to be eligible for the study. Deviating from the originally planned sample size of $n=16$, only $n=15$ were administered the IMP. 5 had to be excluded before IMP administration due to newly developed exclusion criteria between screening and hospitalisation. Demographics of the volunteers are shown in table $1 . \underline{n} M L$ were detectable in none of the volunteers before and in all volunteers after injection of the IMP. Although all volunteers received the s.c. injection of the IMP from the same experienced investigator, individual serum concentration-time profiles varied considerably: Volunteers No 1 to 9 and 14 (10/15 volunteers (67\%) showed a fast increase with high concentrations of $\mathrm{nML}$ followed by a slow decrease. A second increase was observed in volunteers No 2, 5, 9 and $14(4 / 15,27 \%)$. The remaining 5/15 volunteers (33\%), i.e. volunteers No 10 to 13 and 15, had an undulating course with low levels of nML-concentrations. At the final examination (day $14+/-3$ days after injection) serum nML-concentrations were not detectable in $5 / 15$ volunteers but $9 / 15$ volunteers $(60 \%)$ had still measurable nMLconcentrations. For one volunteer the last scheduled nML-concentration could not be determined because he did not appear to the last examination. The course of nMLconcentrations is shown in Figure 1, the pharmacokinetic data are presented in Table $\underline{2}$ and $\underline{3}$. The mean serum peak concentration was observed at 01:00 hour post-dose. By the end of the study the curve had not yet, but almost returned to pre-dose values. 
The arithmetic means of $\mathrm{C}_{\max }$ and $\mathrm{AUC}(0-\infty)$ amounted to $1043 \mathrm{pg} / \mathrm{ml}$ and $8395 \mathrm{~h} * \mathrm{pg} / \mathrm{ml}$, respectively. $\mathrm{t}_{\max }$ ranged from 0.3 to 336.0 hours with a median of 2.0 hours. A calculated concentration of $3.7 \mathrm{ng} \mathrm{nML} / \mathrm{ml}$ for the highest signal of the study as determined in volunteer No $3,1 \mathrm{~h}$ after injection corresponds to $56 \%$ serum-availability for this time point $(100 \%=6.6$ $\mathrm{ng} / \mathrm{ml})$. Calculation of $\lambda_{\mathrm{z}}$ and $\mathrm{t}_{1 / 2}\left(\mathrm{t}_{1 / 2}=\ln 2 / \lambda_{\mathrm{z}}\right)$ was in none of the volunteers possible due to non-linear concentration-time profiles. The $\operatorname{AUC}\left(0-t_{\text {last }}\right)$ was determined by trapezoidal analysis. In volunteers No. 2, 3, $9-13$ and $15, \operatorname{AUC}\left(\mathrm{t}_{\text {last }}-\infty\right)$ could not be determined because the nML-concentration-time curves could not be extrapolated to $\infty$ due to non-linearity. In volunteers No. 1,4 to 8 and 14 , $\mathrm{AUC}\left(\mathrm{t}_{\text {last }}-\infty\right)$ did not need to be determined because nMLconcentrations decreased below detection threshold within the time period of blood sampling. For volunteers in whom the nML serum concentrations had not decreased below detection threshold of $100 \mathrm{pg} / \mathrm{ml}$ in the time period of blood sampling, i.e. for 10/15 volunteers (67\%), $\operatorname{AUC}(0-\infty)$ and $\mathrm{CL}_{\mathrm{sc}}(0-\infty)$ were not determinable.

Compared to baseline, activated NK-cells (CD54+/CD94+) as proportion of total NK-cells (CD16+/CD56+) did not significantly change after injection of the IMP.

There were no serious adverse events whether drug-related or not. 53/55 treatment emergent AEs were assessed by the investigator to be at least possibly related to the IMP and all 15 volunteers experienced one or more $\mathrm{AE}$ with at least possible causal relationship to the IMP. Only 3/55 treatment emergent AEs observed in 2/15 volunteers (13\%) were of severe intensity (flue-like symptoms in 2 , nausea in 1 volunteer).

As expected, a local inflammatory reaction at the injection site of abnobaVISCUM ${ }^{\circledR}$ Fraxini $20 \mathrm{mg}$ was observed in almost all study participants (14/15 volunteers, 93\%) and 15/15 volunteers had an increase of body temperature to $>37.5^{\circ} \mathrm{C}$ (Figure 2) which was accompanied by flu like symptoms in all and nausea in 8 volunteers. 11/15 volunteers (73.5 $\%)$ took concomitant medication because of pain at the injection site during hospitalisation and 3/15 volunteers also after discharge from the clinical trial center. In 12/15 volunteers (80 $\%)$ the inflammatory reaction persisted beyond the final study examination the longest duration of the reaction amounting to 95 days. 
With regard to laboratory evaluations, no clinically significant deviations of haematological, biochemical and urinalysis parameters from the normal range were observed at the final examination (day 14+/-3 days) after administration of the IMP (Table 4). None of the volunteers showed a clinically significant abnormality in the ECG throughout the study. Apart from the above described local inflammatory reactions at the injection site no clinically significant abnormalities were found during the physical examination.

Discussion

This study investigated for the first time pharmacokinetics of naturally occurring mistletoe

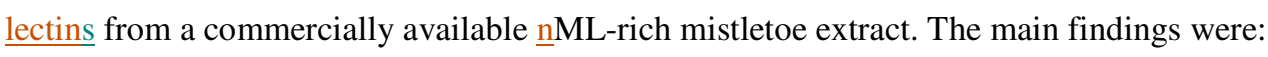

1. $\underline{n} M L$ from mistletoe extracts can be detected in the human serum after a single subcutaneous injection.

2. Detectability of $\mathrm{nML}$ in serum is considerably longer than that of recombinant type II ribosome inactivating protein (rML) analogous to mistletoe lectin.

3. Pharmacokinetics of $\underline{n} \mathrm{ML}$ after subcutaneous injection is subject to considerable interindividual variability.

Due to non-linear kinetic s the half-life of nML could not be determined, since calculation of half-life is meaningless in case of non-linear concentration-time-profiles. Because half-life of rML is only 13 minutes [12] and in 9/15 of our volunteers nML was detectable even two weeks after injection, a longer detectability of nML in serum can be concluded, even though the route of application was intravenous in the study of Schöffski et al. and subcutaneous in our study. In contrast to rML, nML is glycosylated and has different kinetics of association and dissociation with glycoconjugates. Furthermore, B-chains of rML and nML differ in binding specifity to carbohydrates [1]]. This may cause different uptake and distribution in blood and tissue and could explain the longer detectability of nML in serum. Cytotoxicity of nML and rML were similar in MOLT-4 cell cultures [1]]. In vitro studies using human peripheral blood mononuclear cells, however, significant differences of rML and nML on cell viability and immunomodulation were found [1 $\underline{8}]$.

A long detectability in serum regarded as advantageous for therapeutic use might be opposed by the strong interindividual differences of nML pharmacokinetics after subcutaneous injection. 
The high interindividual differences that were observed although all volunteers were injected by the same investigator in the same abdominal quadrant may be attributed to different patterns of nML binding to carbohydrates and release from the subcutaneous tissue. The observed non-linear pharmacokinetics of the large ${ }_{n} M L$ molecules (50-63kDa) would support this hypothesis. Pharmacokinetic investigations in rats, performed within a subchronic toxicity study with abnobaVISCUM ${ }^{\circledR}$ Fraxini $20 \mathrm{mg}$ also showed high interindividual differences between the animals under GLP-conditions [19]. Cross-reactivities could potentially have affected the test results but are unlikely. Cross-reactivity to cbML can be excluded because of its completely different structure and because comparing experiments with antibodies to NML I-III and cbML in healthy volunteers and tumor patients did not show cross-reactivity [10]. Because nML I-III is highly antigenic after parenteral injection (almost $100 \%$ of nML exposed individuals develop anti-nML antibodies) and anti-nML antibodies are absent in individuals without previous exposure to parenteral mistletoe preparations [20], a cross reactivity to environmental factors like diet or inhalative environmental antigens can also widely be excluded. Metabolites of nML are, to our knowledge, not known.

We choose the subcutaneous application, because this is the common form for mistletoe preparations and abnobaVISCUM ${ }^{\circledast}$ Fraxini $20 \mathrm{mg}$ has only the marketing authorisation for subcutaneous injection. Also pharmacokinetics of other molecules, like soluble, recombinant interleukin-4 receptor (sIL-4R)[21] and erythropoietin [22], with a size comparable to nML of 140- and $34 \mathrm{kDa}$, respectively, were investigated after subcutaneous (s.c.) injection. Murine sIL-4R elimination half life was 2.3 hours following intravenous injection and 6.2 hours after s.c. injection. Also the sIL-4R blood level was lower after s.c. injection but bioavailability was comparable. Subcutaneously applicated erythropoietin, given to 48 volunteers, resulted in considerable inter-individual differences of $\mathrm{C}_{\max }$. from 40 to 95 IU/1. The half life was about 3 times longer than after intravenous application. Despite the comparability with these endogenously occurring substances is limited, the findings of a longer detectability and higher inter-individual differences are in principle in accordance with our results. Initial high doses of subcutaneously applied a abnobaVISCUM ${ }^{\circledR}$ Fraxini $20 \mathrm{mg}$ have a variety of side effects, especially fever and related symptoms and strong local reactions. The manufacturer recommends, therefore, lower doses for initial therapy. In one publication, however, even higher doses ( 2 ampoules abnobaVISCUM ${ }^{\circledR}$ Fraxini $20 \mathrm{mg}$ ) were applied initially and had beneficial effects in 23 patients with advanced hepatocellular carcinoma [23]. The non-hematological toxicity included fever, erythema and pain at the injection site as in our volunteers. No hematological toxicity was observed. This published clinical experience 
encouraged us to regard 1 ampoule abnobaVISCUM ${ }^{\circledR}$ Fraxini $20 \mathrm{mg}$ as safe for this phase I pharmacokinetic study. The hypothesis, that the percentage of activated NK-cells (CD54+/CD94+) increases after a single injection of abnobaVISCUM ${ }^{\circledR}$ Fraxini 20mg could not be confirmed.

Since it is now known that natural mistletoe lectins are absorbed into the blood after subcutaneous injection of abnobaVISCUM ${ }^{\circledR}$ Fraxini $20 \mathrm{mg}$ in healthy volunteers, pharmacokinetic considerations should also be addressed in subsequent clinical trials with mistletoe preparations for oncological patients.

Acknowledgment

The study was sponsored by Abnoba $\mathrm{GmbH}_{2}$ Pforzheim, Germany.

References

1. Horneber MA, Bueschel G, Huber R, Linde K, Rostock M (2008) Mistletoe therapy in oncology. Cochrane Database Syst Rev (2):CD003297

2. Ribéreau-Gayon G, Jung ML, Frantz M, Anton R (1997) Modulation of cytotoxicity and enhancement of cytokine release induced by Viscum album L. extracts or mistletoe lectins. Anticancer Drugs 8 Suppl 1:S3-8

3. Rostock M, Huber R, Greiner T, Fritz P, Scheer R, Schueler J, Fiebig HH (2005) Anticancer activity of a lectin-rich mistletoe extract injected intratumorally into human pancreatic cancer xenografts. Anticancer Res 25(3B):1969-1975

4. Huber R, Rostock M, Goedl R, Lüdtke R, Urech K, Buck S, Klein R (2005) Mistletoe treatment induces GM-CSF- and IL-5 production by PBMC and increases blood granulocyte- and eosinophil counts: a placebo controlled randomized study in healthy subjects. Eur J Med Res 10(10):411-418

5. Franz H (1985) Inhaltsstoffe der Mistel (Viscum album L.) als potentielle Arzneimittel. Pharmazie 40:97-104

6. Franz H (1991) Mistletoe lectins (2). In: Franz, H (ed) Advances in Lectin Research, Springer Berlin, pp 33-50 
7. Franz H, Friemel H, Buchwald S, Plantikow A, Kopp J, Körner I.J (1990) The A chain of lectin 1 from European mistletoe (Viscum album) induces interleukin-I and interleukin-II in human mononuclear cells. In: Kocourek J, Freed DLJ (eds) Lectins: Biology, Biochemistry, Clinical Biochemistry Vol. 7, Sigma Chemical Company, St. Louis, Missouri, USA, pp. 247-250

8. Stirpe F, Barbieri L, Batteli MG, Soria M, Lappi DA (1992) Ribosome-inactivating proteins from plants: present status and future prospects. Bio Technology 10:405-412

9. Büssing, A (2000) Biological and pharmacological properties of Viscum album L. In: Büssing, A (ed) Mistletoe, the Genus Viscum. Amsterdam (2000)

10. Klein R, Franz M, Wacker R, Classen K, Scheer R, Von Laue HB, Stoeva S, Voelter W (2004) Demonstration of antibodies to the chitin-binding mistletoe lectin (cbML) in tumor patients before and during therapy with an aqueous mistletoe extract. Eur J Med Res 9(6):316-22

11. Adler M, Langer M, Witthohn K, Eck J, Blohm D, Niemeyer CM (2003) Detection of rViscumin in plasma samples by immuno-PCR.; Biochem Biophys Res Comm 300: $757-763$

12. Schöffski P, Riggert S, Fumoleau P, Campone M, Bolte O, Marreaud S, Lacombe D, Baron B, Herold M, Zwierzina H, Wilhelm-Ogunbiyi K, Lentzen H, Twelves C (2004) Phase I Trial of intravenous aviscumine (rViscumin) in patients with solid tumors: a study of the European Organization for Research of Cancer New Drug Development Group. Ann Oncol 15:1816 - 1824

13. Krause SW, Gastpar R, Andreesen R, Gross C, Ullrich H, Thonigs G, Pfister K, Multhoff G (2004) Treatment of colon and lung cancer patients with ex vivo heat shock protein 70-peptide-activated, autologous natural killer cells: a clinical phase I trial. Clin Cancer Res 10(11):3699-3707

14. Samtleben R, Kiefer M, Luther P (1985) Characterization of the different lectins from Viscum album L. (mistletoe) and their structural relationships with the agglutinins from Abrus precaratorius and Ricinus communis. In: Kocourek J, Freed DLJ (eds) Lectins: Biology, Biochemistry, Clinical Biochemistry Vol. 4, Sigma Chemical Company, St. Louis, Missouri, USA, pp 617-626

15. Franz M, Vollmer S, Wacker R, Jäger S, Scheer R, Stoeva S, Lehmann R, Tsitsilonis $\underline{\mathrm{R}, \text { Voelter W (2005) Isolation and quantification of the chitin-binding mistletoe lectins }}$ 
(cbMLs) from mistletoe extracts and the validation of this method. In: Scheer R, Bauer $\underline{\text { R, Becker H, Fintelmann V, Kemper FH, Schilcher H (eds) Fortschritte in der }}$ Misteltherapie, KVC Verlag, pp 69-81

16. Adler, M., Wacker, R, Niemeyer, CM (2008) Sensitivity by combination: immunoPCR and related technologies. Analyst 133(6):702-718

17. Eck J, Langer M, Möckel B, Witthohn K, Zinke H, Lentzen H (1999) Characterization of recombinant and plant-derived mistletoe lectin and their B-chains. Eur J Biochem 265(2):788-797

18. Elsässer-Beile U, Voss M, Schühle R, Wetterauer U (2000) Biological effects of natural and recombinant mistletoe lectin and an aqueous mistletoe extract on human monocytes and lymphocytes in vitro. J Clin Lab Anal 14(6):255-259

19. ADVINUS Therapeutics Private Limited (2009) Mistletoe extract AbnobaViscum Fraxini 20mg: 90 day study in Sprague-Dawley rats by subcutaneous route with toxicokinetics and 4 week recovery period. ADVINUS report-No. G5087-90R-SC, Bangalore, India

20. Klein R, Classen K, Berg PA, Lüdtke R, Werner M, Huber R (2002) In vivo-induction of antibodies to mistletoe lectin-1 and viscotoxin by exposure to aqueous mistletoe extracts: a randomised double-blinded placebo controlled phase I study in healthy individuals. Eur J Med Res 7(4):155-163.

21. Jacobs CA, Lynch DH, Roux ER, Miller R, Davis B, Widmer MB, Wignall J, VandenBos T, Park LS, Beckmann MP (1991) Characterization and pharmacokinetic parameters of recombinant soluble interleukin-4 receptor. Blood. 77(11):2396-2403.

22. Hayashi N, Kinoshita H, Yukawa E, Higuchi S (1998) Pharmacokinetic analysis of $\underline{\text { subcutaneous erythropoietin administration with nonlinear mixed effect model }}$ including endogenous production. Br J Clin Pharmacol. 46(1):11-9.

23. Mabed M, El-Helw L, Shamaa S (2004) Phase II study of viscum fraxini-2 in patients with advanced hepatocellular carcinoma. Br J Cancer 90(1):65-69 
Table 1: Volunteer demographics

\begin{tabular}{|c|c|c|c|c|c|c|c|}
\hline & \multicolumn{7}{|c|}{ Demographic characteristics $(n=15)$} \\
\hline & & & & & & $95 \%$ Confic & nce Interval \\
\hline & $\begin{array}{l}\text { Arithmetic } \\
\text { mean }\end{array}$ & SD & Minimum & Median & Maximum & Lower limit & Upper limit \\
\hline Age [years] & 31.4 & 6.3 & 18.0 & 30.0 & 42.0 & 18.0 & 42.0 \\
\hline Height [cm] & 181.3 & 6.4 & 171.0 & 180.0 & 193.0 & 171.0 & 193.0 \\
\hline Weight [kg] & 78.0 & 10.4 & 65.0 & 74.0 & 99.0 & 65.0 & 99.0 \\
\hline BMI $\left[\mathrm{kg} / \mathrm{m}^{2}\right]$ & 23.7 & 2.4 & 20.3 & 23.5 & 27.7 & 20.3 & 27.7 \\
\hline
\end{tabular}


Table 2: Summary of the pharmacokinetic parameters of natural mistletoe lectins

Pharmacokinetic parameters of natural mistletoe lectins after one single subcutaneous dose of abnobaVISCUM ${ }^{\circledR}$ Fraxini $20 \mathrm{mg}$

\begin{tabular}{|c|c|c|c|c|c|c|c|c|c|c|}
\hline & $n$ & $\begin{array}{l}\text { Mini- } \\
\text { mum }\end{array}$ & $\begin{array}{l}\text { Maxi- } \\
\text { mum }\end{array}$ & $\begin{array}{l}\text { Arith- } \\
\text { metic } \\
\text { Mean }\end{array}$ & $\begin{array}{l}\text { Standard } \\
\text { Deviation }\end{array}$ & $\begin{array}{l}\text { Lower } \\
\text { Quar- } \\
\text { tile }\end{array}$ & $\begin{array}{l}\text { Medi- } \\
\text { an }\end{array}$ & $\begin{array}{l}\text { Upper } \\
\text { Quar- } \\
\text { tile }\end{array}$ & $\begin{array}{l}\text { Lower } \\
\text { Limit } \\
95 \% \mathrm{Cl}\end{array}$ & $\begin{array}{c}\text { Upper } \\
\text { Limit 95\% } \\
\text { Cl }\end{array}$ \\
\hline $\mathrm{C}_{\max }[\mathrm{pg} / \mathrm{ml}]$ & 15 & 188,7 & 3738 & 1043 & 1162 & 283 & 594 & 1029 & 189 & 3738 \\
\hline$t_{\max }[h]$ & 15 & 0,3 & 336,0 & 26,4 & 85,8 & 1,0 & 2,0 & 10,0 & 0,3 & 336 \\
\hline $\begin{array}{l}\operatorname{AUC}(0- \\
\text { tlast }) \\
{\left[h^{*} p g / m l\right]}\end{array}$ & 15 & 1401 & 125405 & 34652 & 35786 & 4533 & 20984 & 58116 & 1401 & 125405 \\
\hline $\begin{array}{l}\operatorname{AUC}(0-\infty)^{*} \\
{\left[h^{*} p g / m l\right]}\end{array}$ & 7 & 1401 & 20984 & 8395 & 8173 & 2552 & 4533 & 19084 & 1401 & 20984 \\
\hline $\begin{array}{l}\operatorname{CLsc}(0- \\
72 \mathrm{~h})^{* *}[\mathrm{~L} / \mathrm{h}]\end{array}$ & 15 & 428 & 14279 & 3819 & 3543 & 1510 & 2739 & 4589 & 428 & 14279 \\
\hline $\begin{array}{l}\operatorname{CLsc}(0- \\
336 \mathrm{~h})^{\star *} \\
{[\mathrm{~L} / \mathrm{h}]}\end{array}$ & 15 & 160 & 14279 & 2779 & 4001 & 344 & 953 & 4412 & 160 & 14279 \\
\hline $\begin{array}{l}\operatorname{CLsc}(0-\infty)^{*} \\
{[L / h]}\end{array}$ & 7 & 953 & 14279 & 5412 & 4701 & 1048 & 4412 & 7837 & 953 & 14279 \\
\hline
\end{tabular}

Maximum plasma-concentration $\mathrm{C}_{\max }$

Time to reach maximum plasma-concentration $t_{\max }[\mathrm{h}]$ and Elimination rate constant $\lambda z[1 / \mathrm{h}]$ : could not be determined in any of the volunteers due to non-linear course of the concentration-time profiles.

| Area under the plasma-concentration-time-curve AUC(tlast- $\infty$ ): could not be determined, since extrapolation of the concentration-time-curves from last datapoint to inifinite time was not possible in volunteers No. 2,3, 9-13 and 15 due to non-linear run of the curves and was not necessary in volunteers No. 1, 4-8 and 14 because mistletoe lectin serum concentrations had already decreased to or below predose values within the time period of blood sampling, i.e. within the timepoint of last blood sampling (tlast).

| ${ }^{*} \mathrm{AUC}(0-\infty)$ and apparent subcutaneous clearance $\operatorname{CLsc}(0-\infty)$ : The summary statistics for $\mathrm{AUC}(0-\infty)$ and $\mathrm{CLsc}(0-$ $\infty$ ) included only $n=7$ volunteers, i.e. volunteers No. 1, 4-8 and 14 in whom the total AUC was equal to the AUC (tlast- $\infty)$. Volunteers No. 2,3, 9-13 and 15 could not be taken into account for the summary statistics of $\operatorname{AUC}(0-\infty)$ and $\operatorname{CLsc}(0-\infty)$, because in these cases AUC(tlast- $\infty)$ could not be determined (see above).

${ }^{*} \mathrm{CLsc}(0-72 \mathrm{~h})$ and CLsc(0-336h): Because the apparent subcutaneous clearance CLsc (CLsc $\left.(0-\infty)\right)$ could not be determined in most of the volunteers, the apparent subcutaneous clearances for the time periods from 0 to 72 hours $(\mathrm{CLsc}(0-72 \mathrm{~h}))$ and from 0 to 336 hours $(\mathrm{CLsc}(0-336 \mathrm{~h}))$ were determined in all volunteers. 
Table $\underline{3}$ : Individual pharmacokinetic parameters of natural mistletoe lectins

Pharmacokonetic parameters of natural mistletoe lectins after one single sc dose of abnobaVISCUM ${ }^{\circledast}$ Fraxini $20 \mathrm{mg}$

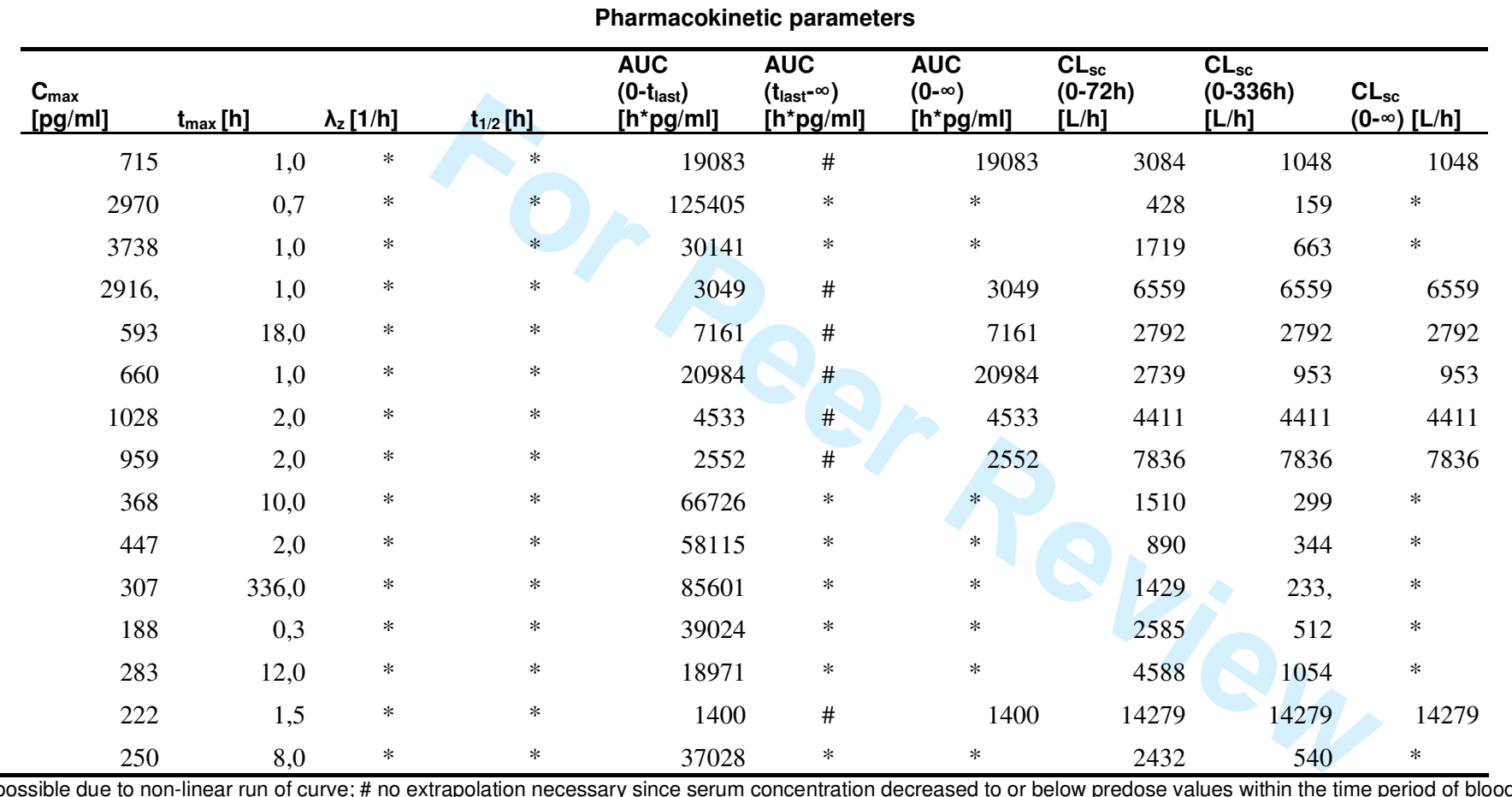


Table 4: Safety laboratory parameters: Difference from before to $14 \pm 3$ days after subcutaneous application of $1 \mathrm{ml}$ abnobaVISCUM ${ }^{(\beta}$ Fraxini $20 \mathrm{mg}(\mathrm{n}=15)$

\begin{tabular}{|c|c|c|c|c|c|}
\hline Parameter & Lower Quartile & $\underline{\text { Median }}$ & Upper Quartile & $\frac{\text { Lower Limit 95\% }}{\underline{\mathrm{Cl}}}$ & $\frac{\text { Upper Limit 95\% }}{\underline{\text { Cl }}}$ \\
\hline Hemoglobin $(\mathrm{g} / \mathrm{dl})$ & $\underline{-0.9}$ & $\underline{-0.2}$ & $\underline{0}$ & $\underline{-1.5}$ & $\underline{1.4}$ \\
\hline White blood count / $\mu \mathrm{l}$ & $\underline{70}$ & $\underline{640}$ & $\underline{1220}$ & $\underline{-990}$ & $\underline{2680}$ \\
\hline Platelet count / $\mu$ l & $\underline{58000}$ & $\underline{108000}$ & $\underline{136000}$ & $\underline{3000}$ & $\underline{18000}$ \\
\hline Creatinine $(\mathrm{mg} / \mathrm{dl})$ & $\underline{0}$ & $\underline{0}$ & $\underline{0.1}$ & $\underline{-0.1}$ & $\underline{0.3}$ \\
\hline$\underline{\text { Uric acid }(\mathrm{mg} / \mathrm{dl})}$ & $\underline{-0.3}$ & $\underline{0.3}$ & $\underline{0.9}$ & -1.0 & 1.2 \\
\hline$\underline{\text { Sodium }(\mathrm{mmol} / \mathrm{l})}$ & -1 & 1 & $\underline{2}$ & $\underline{-5}$ & $\underline{3}$ \\
\hline$\underline{\text { Potassium }(\mathrm{mmol} / \mathrm{l})}$ & $\underline{0.1}$ & $\underline{0.3}$ & $\underline{0.7}$ & $\underline{-0.3}$ & $\underline{1.2}$ \\
\hline Calcium (mmol/l) & $\underline{0}$ & $\underline{0.1}$ & $\underline{0.2}$ & $\underline{0}$ & $\underline{0.3}$ \\
\hline Creatinkinase (U/I) & $\underline{-39}$ & 1 & $\underline{19}$ & $\underline{-80}$ & $\underline{119}$ \\
\hline $\begin{array}{l}\text { Alanine aminotransferase } \\
(\mathrm{U} / \mathrm{l})\end{array}$ & 1 & $\underline{5}$ & $\underline{20}$ & $\underline{-5}$ & $\underline{31}$ \\
\hline $\begin{array}{l}\text { Aspartate } \\
\underline{\text { aminotransferase }(\mathrm{U} / \mathrm{l})}\end{array}$ & -1 & $\underline{2}$ & $\underline{4}$ & $\underline{-6}$ & $\underline{11}$ \\
\hline $\begin{array}{l}\text { Lactate dehydrogenase } \\
\underline{(\mathrm{U} / \mathrm{l})}\end{array}$ & $\underline{11}$ & $\underline{22}$ & $\underline{27}$ & $\underline{-10}$ & $\underline{48}$ \\
\hline $\begin{array}{l}\text { Gamma } \\
\text { gluatmyltransferase (U/l) }\end{array}$ & $\underline{0}$ & $\underline{3}$ & $\underline{8}$ & $\underline{-2}$ & $\underline{30}$ \\
\hline Bilirubin (mg/dl) & $\underline{-0.3}$ & $\underline{-0.1}$ & $\underline{0}$ & $\underline{-1.3}$ & $\underline{0.4}$ \\
\hline Alpha amylase (mg/dl) & $\underline{-2}$ & $\underline{4}$ & 11 & $\underline{-5}$ & $\underline{25}$ \\
\hline Total protein $(\mathrm{g} / \mathrm{dl})$ & $\underline{0}$ & $\underline{0.5}$ & $\underline{0.8}$ & $\underline{-0.4}$ & $\underline{1.2}$ \\
\hline Albumin $(\mathrm{g} / \mathrm{dl})$ & $\underline{-0.1}$ & $\underline{0.4}$ & $\underline{0.6}$ & $\underline{-0.4}$ & $\underline{0.9}$ \\
\hline C-reactive protein $(\mathrm{mg} / \mathrm{dl})$ & $\underline{0}$ & $\underline{0.2}$ & $\underline{0.5}$ & $\underline{0}$ & $\underline{0.7}$ \\
\hline$\underline{\text { Cholesterol }(\mathrm{mg} / \mathrm{dl})}$ & -7 & $\underline{2}$ & $\underline{14}$ & $\underline{-35}$ & $\underline{32}$ \\
\hline Triglycerides (mg/dll) & $\underline{-19}$ & $\underline{5}$ & $\underline{52}$ & -62 & $\underline{103}$ \\
\hline$\underline{\text { Glucose }(\mathrm{mg} / \mathrm{dl})}$ & $\underline{-3}$ & -1 & $\underline{4}$ & $\underline{-4}$ & $\underline{21}$ \\
\hline
\end{tabular}




\section{Page 19 of 42}



Figure 1: Individual natural mistletoe lectin concentration-time profiles $(n=15)$ 




Figure 1a: Individual natural mistletoe lectin concentration-time profiles $(n=15)$

Formatted: Highlight
Deleted: $\mathbf{M}$
Formatted: Highlight




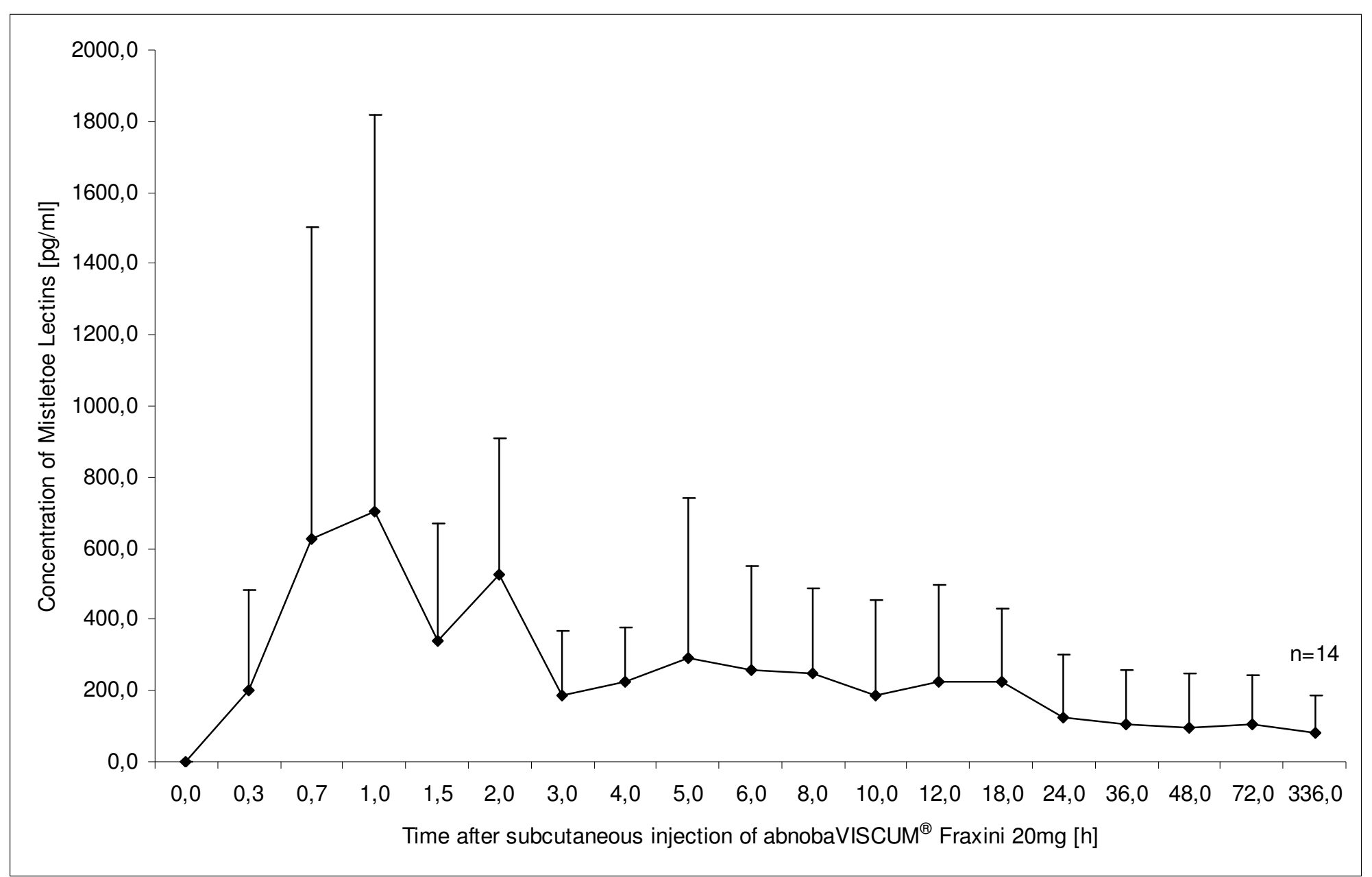

Figure 1b: Arithmetic Mean ( \pm standard deviation) of natural mistletoe lectin concentration-time profiles $(n=15)$
Formatted: Highlight

Deleted: M

Formatted: Highlight 


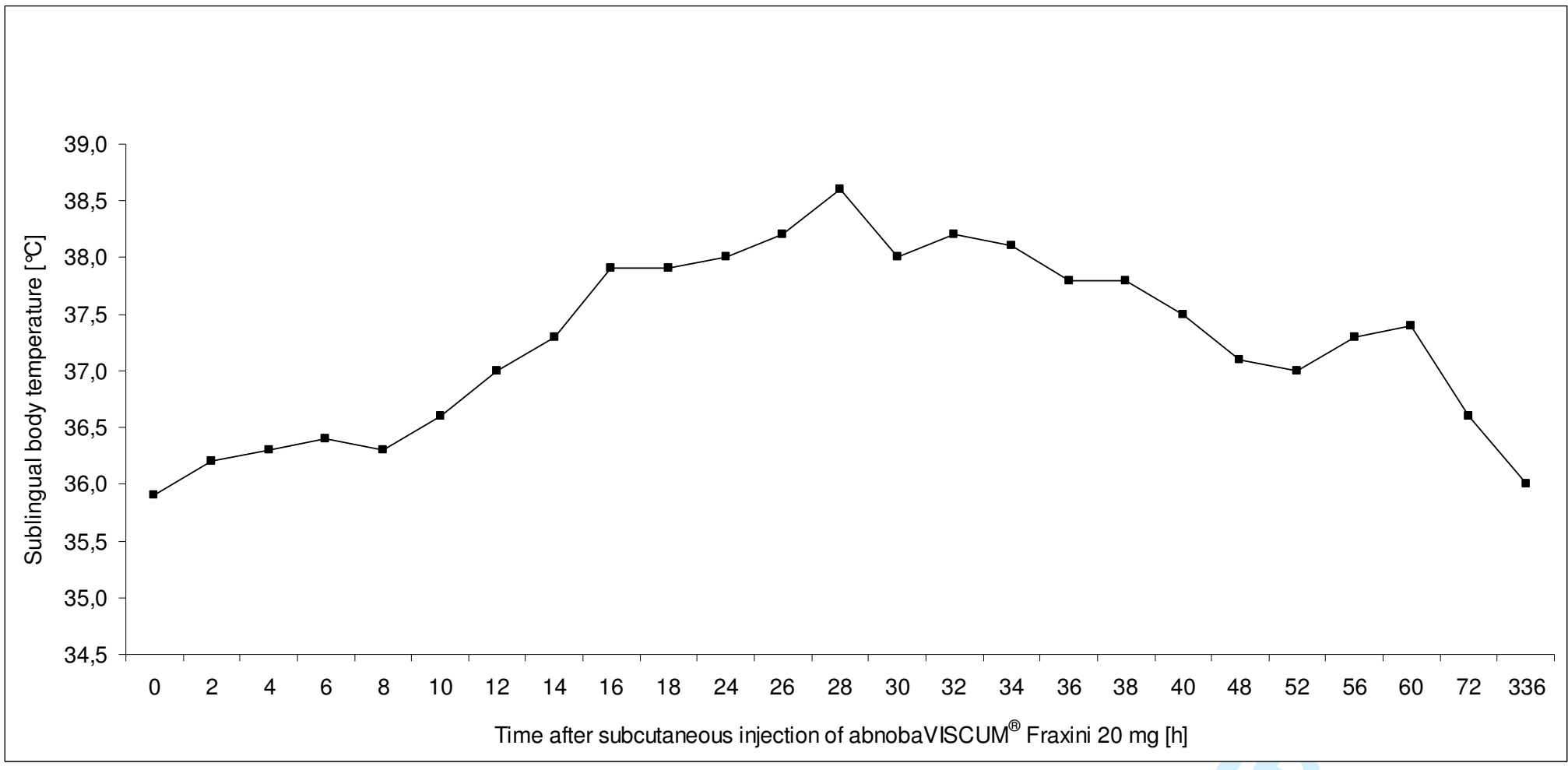

Figure 2: Arithmetic mean of sublingual body temperature after $(n=15)$ 


\section{Pharmacokinetics of natural mistletoe lectins after subcutaneous injection}

Roman Huber ${ }^{1}$, Jürgen Eisenbraun ${ }^{2}$, Barbara Miletzki $^{3}$, Michael Adler ${ }^{4}$, Rainer Scheer ${ }^{2}$, Reinhild Klein ${ }^{5}$, Christoph H. Gleiter ${ }^{3}$

${ }^{1}$ Department of Environmental Health Sciences, University Hospital Freiburg, Germany

2 Abnoba GmbH, Pforzheim, Germany

${ }^{3}$ CenTrial GmbH, Tübingen/Ulm, Germany

${ }^{4}$ Chimera Biotec GmbH, Dortmund, Germany

${ }^{5}$ Department of Internal Medicine II, University of Tübingen, Germany

Corresponding author

Dr. Roman Huber

Department of Environmental Health Sciences

University Hospital Freiburg

Breisacher Str. 115b

D-79106 Freiburg

Germany

Phone: 00497612708201

Fax: 00497612708323

Email: roman.huber@uniklinik-freiburg.de 


\section{Abstract}

Purpose: Knowledge of natural mistletoe lectins (nML) pharmacokinetics can be regarded as essential for further rational studies with mistletoe preparations. Studies with intravenous application of a recombinant type II ribosome inactivating protein (rML) analogous to $\mathrm{nML}$ revealed a short half life of about 13 minutes in cancer patients. This open-label, phase I, monocenter clinical trial was performed in order to describe the pharmacokinetics of nML. Methods: In 15 healthy male volunteers aged 18-42 years nML were detected with a modified sandwich Immuno-PCR technique (Imperacer®, Chimera Biotec) after single subcutaneous injection of a mistletoe extract (abnobaVISCUM ${ }^{\circledR}$ Fraxini 20mg) with marketing authorisation, containing about $20 \mu \mathrm{g}$ nML per millilitre. Secondary objectives were safety and the number of activated natural killer cells (CD54+/CD94+). Results: In none of the volunteers $\mathrm{nML}$ were detectable before the injection and in all volunteers nML were detected in serum samples after the injection. Individual variability however was large. The mean and median peak concentration was reached 1 and 2 hours after injection, respectively. In some of the volunteers nML were still detectable at the final investigation 2 weeks after injection. The injection resulted in fever and flue like symptoms in all volunteers but no serious adverse events occurred. All symptoms and local reactions at the injection site completely disappeared within a range of 4 to 95 days. The number of activated natural killer cells did not change. Conclusions: nML from abnobaVISCUM ${ }^{\circledR}$ Fraxini $20 \mathrm{mg}$ are detectable in serum after a single subcutaneous injection. Detectability is considerably longer compared to intravenous. rML. The subcutaneous injection of this preparation without usual pretreatment with lower doses results in short-lasting fever and other flu-like symptoms.

\section{Key words:}

abnobaVISCUM, anthroposophical medicine, healthy volunteers, phytotherapy, safety, NKcells 
Introduction

Mistletoe preparations are used since decades for supportive cancer treatment within the concept of anthroposophical medicine. Despite more than 40 randomized clinical trials, the efficacy of mistletoe treatment in cancer therapy is yet not clear and discussed controversially [1]. Reasons for this unsatisfactory situation are, that different mistletoe preparations with different ingredients in different concentrations have been tested and that the pharmacology of mistletoe extracts is unclear. Active ingredients of mistletoe extracts are mainly mistletoe lectins (nML), viscotoxins and polysaccharides. From these, nML are the most interesting substances for anticancer activity. They have in in-vitro and animal models been demonstrated to have distinct cytotoxic properties $[2,3]$. In doses below cytotoxicity $\mathrm{nML}$ stimulate the unspecific and specific immune system in humans [4].

ML are glycoproteins and occur naturally in 2 types, the ribosome inactivating proteins of class 2, which are devided in the 3 subtypes nML-I, -II and -III and viscum album chitinbinding ML (cbML). The molecular weight of nML I-III is about $.63 \mathrm{kDa}$. They have very similar biological properties and are composed of a $\mathrm{N}$-glycosidase (A-chain) and a galactoside-recognizing lectin (B-chain), connected by a disulfide bridge [5, 6]. The A-chain inhibits protein synthesis [7, 8]. The B-chain binds to carbohydrate residues on the cell surface, thus entering the cell by receptor-mediated endocytosis and inducing apoptosis of the cell $[8,9]$. The cbML belongs to a different class of lectins with a different structure, low antigenicity and a molecular weight of only about $11 \mathrm{kDa}$ [10]. It is far less toxic than nML IIII and is not included in our analysis.

Recently, the technique to detect nML I-III in nanogram ranges in human serum has been developed [11, 12]. A recombinant type II ribosome inactivating protein (rML) analogous to natural mistletoe lectin I revealed a short half life of about 13 minutes in cancer patients [12]. Knowledge of nML pharmacokinetics can be regarded as important to optimize clinical use and further rational studies with mistletoe preparations. To the first time, we therefore investigated the pharmacokinetics of natural mistletoe lectin from a commercially available mistletoe preparation in humans. 
Patients and Methods

The study was performed as an uncontrolled, non-randomized, open-label, phase I, monocenter clinical trial. Primary outcome was the pharmacokinetics of nML following a single dose $(1 \mathrm{ml})$ of subcutaneously administered abnobaVISCUM ${ }^{\circledR}$ Fraxini $20 \mathrm{mg}$ in healthy male volunteers. Secondary outcomes were safety and activation markers (CD54+/CD94+) on natural killer (NK) cells. This marker was selected, because treatment of patients with metastatic colorectal cancer and lung cancer with NK-cells (CD54+/CD94+) activated by heat shock proteins showed promising anti-tumor effects [13]. We wanted to test the hypothesis, that mistletoe-induced fever activates NK-cells.

The study comprised a screening (examination 1), a period of hospitalisation (examination 2 to 6) from the night before until 72 hours after s.c. injection of the IMP (investigational medicinal product) and a final follow-up (examination 7) on day $14+/-3$ after injection of the IMP. nML-concentrations in volunteers's sera were analysed before and 0.3, 0.7, 1.0, 1.5, 2, 3, $4,5,6,8,10,12,18,24,36,48,72$ and 336 hours after injection of the IMP. Safety laboratory parameters (creatinine, urea, uric acid, sodium, potassium, chloride, calcium, creatine kinase, alanin amino transferase (ALT), aspartate amino transferase (AST), lactate dehydrogenase, alkaline phosphatase, gamma-glutamyl-transferase, total bilirubin, total protein, albumin, alpha-amylase, C-reactive protein (CRP), cholesterol, triglycerides, glucose) were determined at examinations 1, 2, and 7. CD54+/CD94+ NK cells were determined before and 6, 24 and 72 hours after injection of the IMP.

Inclusion criteria were: 18-45 years old non smoking healthy males, body mass index 18.5-28 $\mathrm{kg} / \mathrm{m}^{2}$ with normal values for blood pressure, pulse rate, body temperature, normal haematological, biochemical and coagulation parameters and normal electrocardiogram. Exclusion criteria were signs of any clinically significant disease, regular use of medication, drug abuse, positive urine screening for drugs, positive blood test for ethanol, participation in another clinical trial, previous therapy with mistletoe preparations, history of allergy to a medicinal product, allergic diseases except the investigator considered them as clinically irrelevant for the purpose of this clinical trial, positive HIV, hepatitis B or C serology, regular intake of more than $20 \mathrm{~g}$ ethanol per day, donation of blood within 3 months prior to study entry, difficult peripheral venous access and inability to understand the nature and the extent of the trial. 
Only volunteers who gave written informed consent and met all eligibility criteria were included into the study.

The relevant ethics committee had provided a favourable opinion on the clinical trial prior to study start and the study was performed in compliance with the principles of Good Clinical Practice and the Declaration of Helsinki.

\section{Medication}

AbnobaVISCUM $^{\circledR}$ Fraxini $20 \mathrm{mg}$ is an injectable, endotoxin free plant extract from the European mistletoe species Viscum album L. for the treatment of malignant tumors, tumor recurrences and defined precanceroses. As abnobaVISCUM ${ }^{\circledR}$ Fraxini $20 \mathrm{mg}$ has the highest content of nML (approx. 20.000ng/ml) of all commercially available mistletoe preparations, this preparation was chosen in order to detect $\mathrm{nML}$ in the nanogram range after subcutaneous injection. Mistletoes from deciduous trees like the ash tree, from which abnobaVISCUM ${ }^{\circledR}$ Fraxini is derived, have relatively high proportions of nML I in relation to nML II/III [14] but due to methodological difficulties, no differentiation of the MLs could be performed in the commercial extract. The amount of cbML in abnobaVISCUM ${ }^{\circledR}$ Fraxini $20 \mathrm{mg}$ has been about $1 \mu \mathrm{g} / \mathrm{ml}$ [15]. Each volunteer was given the same single dose $(1 \mathrm{ml})$ of subcutaneously administered abnobaVISCUM ${ }^{\circledR}$ Fraxini 20mg. No dose adjustments were necessary, since the inclusion criteria limited the body mass index of the volunteers to a range of $18.5-28 \mathrm{~kg} / \mathrm{m}^{2}$. Intratumoral injections with abnobaVISCUM ${ }^{\circledR}$ Fraxini $20 \mathrm{mg}$ resulted in highly significant tumor reductions in human pancreatic cancer xenografts [3].

Quantification of nML and activated NK-cells

Each blood sample was put on ice immediately after collection and centrifuged for 10 minutes at $4{ }^{\circ} \mathrm{C}$ and 2500xg. Thereafter, at least $2 \mathrm{ml}$ of serum were immediately frozen and stored at $-80^{\circ} \mathrm{C}$ in the clinical trial center. 
nML in the sera of the volunteers was measured by an ultrasensitive immuno-PCR method $\left(\right.$ Imperacer $\left.^{\circledR}\right)$ [11, 12, 16], which combines protein detection through ELISA with the exponential signal amplification typical for PCR. The method was validated by Chimera Biotech GmbH, Dortmund, Germany for natural mistletoe lectins of abnobaVISCUM $^{\circledR}$ in human serum. It does not discriminate between the nML subtypes I-III. Due to the completely different structure it does not detect cbML. Briefly, the antigen was immobilized on captureantibody coated microplate surfaces directly from the serum samples as delivered for analysis without additional purification. For minimization of background effects, the samples were diluted 1:3 in a detergent-containing sample dilution buffer. Parallel to the samples, a dilution series of the antigen was studied, abnobaVISCUM ${ }^{\circledR}$ Fraxini $20 \mathrm{mg}$, batch no. 407B04 and abnobaVISCUM ${ }^{\circledR}$ Mali 20 mg, batch no. 502B33 (both ABNOBA GmbH, Germany) were used as reference substance. Spiked samples were used as a calibration curve for quantification of the antigen and testing robustness and specifity. Each calibration curve (6000 - $93.75 \mathrm{pg} / \mathrm{ml}$ antigen) was prepared in antigen-free individual serum, taken previous to the application of the antigen. This dilution series was additionally frozen to simulate the effect of freezing on the antigen-containing samples for analysis. Following incubation of the samples and the calibration curve, the immobilized antigen was coupled with a specific antibody-DNA conjugate. The assay was carried out with a lectin-specific tailored Imperacer ${ }^{\circledR}$ Kit (No. 11-030, Chimera Biotec, Germany). Monoclonal mouse-anti-ML antibody 5F5, antiML-I-(A-Chain) and 5H8 Anti-ML-A (Institut für Immunopräparate und Nährmedien GmbH, , Germany) were used as detection- and capture antibody, respectively.

After a washing step the DNA-marker was amplified by real-time PCR. In data analysis, a baseline correction was applied. The instrument software calculates the threshold cycle $(\mathrm{Ct})$, which represents the first PCR cycle at which the reporter signal exceeds the signal of the baseline ("threshold"), and sets it in the phase where the signal increases linearly. Baseline correction and threshold were identical in all validation measurements. $\Delta \mathrm{Ct}$ values were calculated by subtracting the Ct values obtained for each signal from the total number of cycles carried out in the experiment. This purely mathematical conversion facilitates the comparison of the data with conventional ELISA data as $\Delta \mathrm{Ct}$ values are directly proportional to the antigen concentration. 
For the determination of NK cells, heparinized blood was used, and peripheral blood mononuclear cells (PBMC) were isolated by Ficoll-gradient. After staining with PEconjugated anti-CD56, PerCP-conjugated anti-CD45 and FITC conjugated anti-CD94 antibodies (all obtained from Becton-Dickinson [San Jose, CA]) the PBMC were incubated with the respective antibodies or IgG isotype control antibodies (BD Biosciences Pharmingen). A minimum of 10000 lymphocytes were counted. Quadrants were set based upon the isotype controls for each antibody.

\section{Statistics}

No comparison with a control group was planned and no data for comparison did exist. Since the study was to be conducted for exploratory purposes no statistically based sample size calculation was performed. It was planned to include $n=16$ (two groups of $n=8$ ) healthy male volunteers into the trial, because this is a sufficient number to enable evaluation of the single dose-pharmacokinetics of abnobaVISCUM ${ }^{\circledR}$ Fraxini 20mg.

For statistical analyses two populations of clinical trial participants were defined:

1) The pharmacokinetic population which had to include all clinical trial participants who provided evaluable and interpretable pharmacokinetic results during the $72 \mathrm{hrs}$ after dosing of abnobaVISCUM $^{\circledR}$ Fraxini 20mg.

2) The safety population which had to encompass all clinical trial participants who met all eligibility criteria and were included in the clinical trial. 
The analyses of the nML-pharmacokinetics and the immunological activation marker had to be performed on the pharmacokinetic population. The evaluation of safety and tolerability had to be performed on the safety population. Missing or manipulated data had to be corrected if possible. If this was not possible the data were to be treated as missing data.

Results

$\mathrm{N}=35$ volunteers were screened and $n=20$ were found to be eligible for the study. Deviating from the originally planned sample size of $n=16$, only $n=15$ were administered the IMP. 5 had to be excluded before IMP administration due to newly developed exclusion criteria between screening and hospitalisation. Demographics of the volunteers are shown in table 1. nML were detectable in none of the volunteers before and in all volunteers after injection of the IMP. Although all volunteers received the s.c. injection of the IMP from the same experienced investigator, individual serum concentration-time profiles varied considerably: Volunteers No 1 to 9 and 14 (10/15 volunteers (67\%) showed a fast increase with high concentrations of nML followed by a slow decrease. A second increase was observed in volunteers No 2, 5, 9 and 14 (4/15, 27\%). The remaining 5/15 volunteers (33\%), i.e. volunteers No 10 to 13 and 15, had an undulating course with low levels of nML-concentrations. At the final examination (day $14+/-3$ days after injection) serum nML-concentrations were not detectable in $5 / 15$ volunteers but $9 / 15$ volunteers $(60 \%)$ had still measurable nMLconcentrations. For one volunteer the last scheduled nML-concentration could not be determined because he did not appear to the last examination. The course of nMLconcentrations is shown in Figure 1, the pharmacokinetic data are presented in Table 2 and 3. The mean serum peak concentration was observed at 01:00 hour post-dose. By the end of the study the curve had not yet, but almost returned to pre-dose values. 
Compared to baseline, activated NK-cells (CD54+/CD94+) as proportion of total NK-cells (CD16+/CD56+) did not significantly change after injection of the IMP.

There were no serious adverse events whether drug-related or not. 53/55 treatment emergent AEs were assessed by the investigator to be at least possibly related to the IMP and all 15 volunteers experienced one or more AE with at least possible causal relationship to the IMP. Only 3/55 treatment emergent AEs observed in 2/15 volunteers (13\%) were of severe intensity (flue-like symptoms in 2, nausea in 1 volunteer).

As expected, a local inflammatory reaction at the injection site of abnobaVISCUM ${ }^{\circledR}$ Fraxini 20mg was observed in almost all study participants (14/15 volunteers, 93\%) and 15/15 volunteers had an increase of body temperature to $>37.5^{\circ} \mathrm{C}$ (Figure 2) which was accompanied by flu like symptoms in all and nausea in 8 volunteers. 11/15 volunteers (73.5 $\%)$ took concomitant medication because of pain at the injection site during hospitalisation and 3/15 volunteers also after discharge from the clinical trial center. In 12/15 volunteers (80 $\%)$ the inflammatory reaction persisted beyond the final study examination the longest duration of the reaction amounting to 95 days. 
With regard to laboratory evaluations, no clinically significant deviations of haematological, biochemical and urinalysis parameters from the normal range were observed at the final examination (day 14+/-3 days) after administration of the IMP (Table 4). None of the volunteers showed a clinically significant abnormality in the ECG throughout the study. Apart from the above described local inflammatory reactions at the injection site no clinically significant abnormalities were found during the physical examination.

\section{Discussion}

This study investigated for the first time pharmacokinetics of naturally occurring mistletoe lectins from a commercially available nML-rich mistletoe extract. The main findings were:

1. nML from mistletoe extracts can be detected in the human serum after a single subcutaneous injection.

2. Detectability of nML in serum is considerably longer than that of recombinant type II ribosome inactivating protein (rML) analogous to mistletoe lectin.

3. Pharmacokinetics of nML after subcutaneous injection is subject to considerable interindividual variability.

Due to non-linear kinetics the half-life of nML could not be determined, since calculation of half-life is meaningless in case of non-linear concentration-time-profiles. Because half-life of rML is only 13 minutes [12] and in 9/15 of our volunteers nML was detectable even two weeks after injection, a longer detectability of nML in serum can be concluded, even though the route of application was intravenous in the study of Schöffski et al. and subcutaneous in our study. In contrast to rML, nML is glycosylated and has different kinetics of association and dissociation with glycoconjugates. Furthermore, B-chains of rML and nML differ in binding specifity to carbohydrates [17]. This may cause different uptake and distribution in blood and tissue and could explain the longer detectability of nML in serum. Cytotoxicity of nML and rML were similar in MOLT-4 cell cultures [17]. In vitro studies using human peripheral blood mononuclear cells, however, significant differences of rML and nML on cell viability and immunomodulation were found [18].

A long detectability in serum regarded as advantageous for therapeutic use might be opposed by the strong interindividual differences of nML pharmacokinetics after subcutaneous injection. 
The high interindividual differences that were observed although all volunteers were injected by the same investigator in the same abdominal quadrant may be attributed to different patterns of nML binding to carbohydrates and release from the subcutaneous tissue. The observed non-linear pharmacokinetics of the large nML molecules $(50-63 \mathrm{kDa})$ would support this hypothesis. Pharmacokinetic investigations in rats, performed within a subchronic toxicity study with abnobaVISCUM ${ }^{\circledR}$ Fraxini $20 \mathrm{mg}$ also showed high interindividual differences between the animals under GLP-conditions [19]. Cross-reactivities could potentially have affected the test results but are unlikely. Cross-reactivity to cbML can be excluded because of its completely different structure and because comparing experiments with antibodies to nML I-III and cbML in healthy volunteers and tumor patients did not show cross-reactivity [10]. Because nML I-III is highly antigenic after parenteral injection (almost $100 \%$ of nML exposed individuals develop anti-nML antibodies) and anti-nML antibodies are absent in individuals without previous exposure to parenteral mistletoe preparations [20], a cross reactivity to environmental factors like diet or inhalative environmental antigens can also widely be excluded. Metabolites of nML are, to our knowledge, not known.

We choose the subcutaneous application, because this is the common form for mistletoe preparations and abnobaVISCUM ${ }^{\circledR}$ Fraxini $20 \mathrm{mg}$ has only the marketing authorisation for subcutaneous injection. Also pharmacokinetics of other molecules, like soluble, recombinant interleukin-4 receptor (sIL-4R)[21] and erythropoietin [22], with a size comparable to nML of 140- and $34 \mathrm{kDa}$, respectively, were investigated after subcutaneous (s.c.) injection. Murine sIL-4R elimination half life was 2.3 hours following intravenous injection and 6.2 hours after s.c. injection. Also the sIL-4R blood level was lower after s.c. injection but bioavailability was comparable. Subcutaneously applicated erythropoietin, given to 48 volunteers, resulted in considerable inter-individual differences of $\mathrm{C}_{\max }$.from 40 to $95 \mathrm{IU} / \mathrm{l}$. The half life was about 3 times longer than after intravenous application. Despite the comparability with these endogenously occurring substances is limited, the findings of a longer detectability and higher inter-individual differences are in principle in accordance with our results.

Initial high doses of subcutaneously applied abnobaVISCUM ${ }^{\circledR}$ Fraxini 20 mg have a variety of side effects, especially fever and related symptoms and strong local reactions. The manufacturer recommends, therefore, lower doses for initial therapy. In one publication, however, even higher doses (2 ampoules abnobaVISCUM ${ }^{\circledR}$ Fraxini 20mg) were applied initially and had beneficial effects in 23 patients with advanced hepatocellular carcinoma [23]. The non-hematological toxicity included fever, erythema and pain at the injection site as in our volunteers. No hematological toxicity was observed. This published clinical experience 
encouraged us to regard 1 ampoule abnobaVISCUM ${ }^{\circledR}$ Fraxini $20 \mathrm{mg}$ as safe for this phase I pharmacokinetic study. The hypothesis, that the percentage of activated NK-cells (CD54+/CD94+) increases after a single injection of abnobaVISCUM ${ }^{\circledR}$ Fraxini 20mg could not be confirmed.

Since it is now known that natural mistletoe lectins are absorbed into the blood after subcutaneous injection of abnobaVISCUM ${ }^{\circledR}$ Fraxini $20 \mathrm{mg}$ in healthy volunteers, pharmacokinetic considerations should also be addressed in subsequent clinical trials with mistletoe preparations for oncological patients.

\section{Acknowledgment}

The study was sponsored by Abnoba GmbH, Pforzheim, Germany.

References

1. Horneber MA, Bueschel G, Huber R, Linde K, Rostock M (2008) Mistletoe therapy in oncology. Cochrane Database Syst Rev (2):CD003297

2. Ribéreau-Gayon G, Jung ML, Frantz M, Anton R (1997) Modulation of cytotoxicity and enhancement of cytokine release induced by Viscum album L. extracts or mistletoe lectins. Anticancer Drugs 8 Suppl 1:S3-8

3. Rostock M, Huber R, Greiner T, Fritz P, Scheer R, Schueler J, Fiebig HH (2005) Anticancer activity of a lectin-rich mistletoe extract injected intratumorally into human pancreatic cancer xenografts. Anticancer Res 25(3B):1969-1975

4. Huber R, Rostock M, Goedl R, Lüdtke R, Urech K, Buck S, Klein R (2005) Mistletoe treatment induces GM-CSF- and IL-5 production by PBMC and increases blood granulocyte- and eosinophil counts: a placebo controlled randomized study in healthy subjects. Eur J Med Res 10(10):411-418

5. Franz H (1985) Inhaltsstoffe der Mistel (Viscum album L.) als potentielle Arzneimittel. Pharmazie 40:97-104

6. Franz H (1991) Mistletoe lectins (2). In: Franz, H (ed) Advances in Lectin Research, Springer Berlin, pp 33-50 
7. Franz H, Friemel H, Buchwald S, Plantikow A, Kopp J, Körner I.J (1990) The A chain of lectin 1 from European mistletoe (Viscum album) induces interleukin-I and interleukin-II in human mononuclear cells. In: Kocourek J, Freed DLJ (eds) Lectins: Biology, Biochemistry, Clinical Biochemistry Vol. 7, Sigma Chemical Company, St. Louis, Missouri, USA, pp. 247-250

8. Stirpe F, Barbieri L, Batteli MG, Soria M, Lappi DA (1992) Ribosome-inactivating proteins from plants: present status and future prospects. Bio Technology 10:405-412

9. Büssing, A (2000) Biological and pharmacological properties of Viscum album L. In: Büssing, A (ed) Mistletoe, the Genus Viscum. Amsterdam (2000)

10. Klein R, Franz M, Wacker R, Classen K, Scheer R, Von Laue HB, Stoeva S, Voelter W (2004) Demonstration of antibodies to the chitin-binding mistletoe lectin (cbML) in tumor patients before and during therapy with an aqueous mistletoe extract. Eur J Med Res 9(6):316-22

11. Adler M, Langer M, Witthohn K, Eck J, Blohm D, Niemeyer CM (2003) Detection of rViscumin in plasma samples by immuno-PCR.; Biochem Biophys Res Comm 300: $757-763$

12. Schöffski P, Riggert S, Fumoleau P, Campone M, Bolte O, Marreaud S, Lacombe D, Baron B, Herold M, Zwierzina H, Wilhelm-Ogunbiyi K, Lentzen H, Twelves C (2004) Phase I Trial of intravenous aviscumine (rViscumin) in patients with solid tumors: a study of the European Organization for Research of Cancer New Drug Development Group. Ann Oncol 15:1816 - 1824

13. Krause SW, Gastpar R, Andreesen R, Gross C, Ullrich H, Thonigs G, Pfister K, Multhoff G (2004) Treatment of colon and lung cancer patients with ex vivo heat shock protein 70-peptide-activated, autologous natural killer cells: a clinical phase I trial. Clin Cancer Res 10(11):3699-3707

14. Samtleben R, Kiefer M, Luther P (1985) Characterization of the different lectins from Viscum album L. (mistletoe) and their structural relationships with the agglutinins from Abrus precaratorius and Ricinus communis. In: Kocourek J, Freed DLJ (eds) Lectins: Biology, Biochemistry, Clinical Biochemistry Vol. 4, Sigma Chemical Company, St. Louis, Missouri, USA, pp 617-626

15. Franz M, Vollmer S, Wacker R, Jäger S, Scheer R, Stoeva S, Lehmann R, Tsitsilonis R, Voelter W (2005) Isolation and quantification of the chitin-binding mistletoe lectins 
(cbMLs) from mistletoe extracts and the validation of this method. In: Scheer R, Bauer R, Becker H, Fintelmann V, Kemper FH, Schilcher H (eds) Fortschritte in der Misteltherapie, KVC Verlag, pp 69-81

16. Adler, M., Wacker, R, Niemeyer, CM (2008) Sensitivity by combination: immunoPCR and related technologies. Analyst 133(6):702-718

17. Eck J, Langer M, Möckel B, Witthohn K, Zinke H, Lentzen H (1999) Characterization of recombinant and plant-derived mistletoe lectin and their B-chains. Eur J Biochem 265(2):788-797

18. Elsässer-Beile U, Voss M, Schühle R, Wetterauer U (2000) Biological effects of natural and recombinant mistletoe lectin and an aqueous mistletoe extract on human monocytes and lymphocytes in vitro. J Clin Lab Anal 14(6):255-259

19. ADVINUS Therapeutics Private Limited (2009) Mistletoe extract AbnobaViscum Fraxini 20mg: 90 day study in Sprague-Dawley rats by subcutaneous route with toxicokinetics and 4 week recovery period. ADVINUS report-No. G5087-90R-SC, Bangalore, India

20. Klein R, Classen K, Berg PA, Lüdtke R, Werner M, Huber R (2002) In vivo-induction of antibodies to mistletoe lectin-1 and viscotoxin by exposure to aqueous mistletoe extracts: a randomised double-blinded placebo controlled phase I study in healthy individuals. Eur J Med Res 7(4):155-163.

21. Jacobs CA, Lynch DH, Roux ER, Miller R, Davis B, Widmer MB, Wignall J, VandenBos T, Park LS, Beckmann MP (1991) Characterization and pharmacokinetic parameters of recombinant soluble interleukin-4 receptor. Blood. 77(11):2396-2403.

22. Hayashi N, Kinoshita H, Yukawa E, Higuchi S (1998) Pharmacokinetic analysis of subcutaneous erythropoietin administration with nonlinear mixed effect model including endogenous production. Br J Clin Pharmacol. 46(1):11-9.

23. Mabed M, El-Helw L, Shamaa S (2004) Phase II study of viscum fraxini-2 in patients with advanced hepatocellular carcinoma. Br J Cancer 90(1):65-69 
Table 1: Volunteer demographics

\begin{tabular}{|c|c|c|c|c|c|c|c|}
\hline & \multicolumn{7}{|c|}{ Demographic characteristics $(n=15)$} \\
\hline & \multirow[b]{2}{*}{$\begin{array}{l}\text { Arithmetic } \\
\text { mean } \\
\end{array}$} & \multirow[b]{2}{*}{ SD } & \multirow[b]{2}{*}{ Minimum } & \multirow[b]{2}{*}{ Median } & \multirow[b]{2}{*}{ Maximum } & \multicolumn{2}{|c|}{$95 \%$ Confidence Interval } \\
\hline & & & & & & Lower limit & Upper limit \\
\hline Age [years] & 31.4 & 6.3 & 18.0 & 30.0 & 42.0 & 18.0 & 42.0 \\
\hline Height [cm] & 181.3 & 6.4 & 171.0 & 180.0 & 193.0 & 171.0 & 193.0 \\
\hline Weight $[\mathrm{kg}]$ & 78.0 & 10.4 & 65.0 & 74.0 & 99.0 & 65.0 & 99.0 \\
\hline BMI $\left[\mathrm{kg} / \mathrm{m}^{2}\right]$ & 23.7 & 2.4 & 20.3 & 23.5 & 27.7 & 20.3 & 27.7 \\
\hline
\end{tabular}


Table 2: Summary of the pharmacokinetic parameters of natural mistletoe lectins

\begin{tabular}{|c|c|c|c|c|c|c|c|c|c|c|}
\hline \multirow[b]{3}{*}{$\mathrm{C}_{\max }[\mathrm{pg} / \mathrm{ml}]$} & \multicolumn{10}{|c|}{$\begin{array}{l}\text { Pharmacokinetic parameters of natural mistletoe lectins after one single subcutaneous dose } \\
\text { of abnobaVISCUM }{ }^{\boxplus} \text { Fraxini } 20 \mathrm{mg}\end{array}$} \\
\hline & $\mathrm{n}$ & $\begin{array}{l}\text { Mini- } \\
\text { mum }\end{array}$ & $\begin{array}{l}\text { Maxi- } \\
\text { mum }\end{array}$ & $\begin{array}{l}\text { Arith- } \\
\text { metic } \\
\text { Mean }\end{array}$ & $\begin{array}{l}\text { Standard } \\
\text { Deviation }\end{array}$ & $\begin{array}{l}\text { Lower } \\
\text { Quar- } \\
\text { tile }\end{array}$ & $\begin{array}{l}\text { Medi- } \\
\text { an }\end{array}$ & $\begin{array}{l}\text { Upper } \\
\text { Quar- } \\
\text { tile }\end{array}$ & $\begin{array}{l}\text { Lower } \\
\text { Limit } \\
95 \% \mathrm{Cl}\end{array}$ & $\begin{array}{c}\text { Upper } \\
\text { Limit 95\% } \\
\text { Cl }\end{array}$ \\
\hline & 15 & 188,7 & 3738 & 1043 & 1162 & 283 & 594 & 1029 & 189 & 3738 \\
\hline $\mathrm{t}_{\max }[\mathrm{h}]$ & 15 & 0,3 & 336,0 & 26,4 & 85,8 & 1,0 & 2,0 & 10,0 & 0,3 & 336 \\
\hline $\begin{array}{l}\operatorname{AUC}(0- \\
\text { tlast) } \\
{\left[\mathrm{h}^{\star} \mathrm{pg} / \mathrm{ml}\right]}\end{array}$ & 15 & 1401 & 125405 & 34652 & 35786 & 4533 & 20984 & 58116 & 1401 & 125405 \\
\hline $\begin{array}{l}\mathrm{AUC}(0-\infty)^{*} \\
{\left[\mathrm{~h}^{*} \mathrm{pg} / \mathrm{ml}\right]}\end{array}$ & 7 & 1401 & 20984 & 8395 & 8173 & 2552 & 4533 & 19084 & 1401 & 20984 \\
\hline $\begin{array}{l}\operatorname{CLsc}(0- \\
72 h)^{\star \star}[L / h]\end{array}$ & 15 & 428 & 14279 & 3819 & 3543 & 1510 & 2739 & 4589 & 428 & 14279 \\
\hline $\begin{array}{l}\mathrm{CLsc}(0- \\
336 \mathrm{~h})^{* *} \\
{[\mathrm{~L} / \mathrm{h}]}\end{array}$ & 15 & 160 & 14279 & 2779 & 4001 & 344 & 953 & 4412 & 160 & 14279 \\
\hline $\begin{array}{l}\operatorname{CLsc}(0-\infty)^{*} \\
{[\mathrm{~L} / \mathrm{h}]}\end{array}$ & 7 & 953 & 14279 & 5412 & 4701 & 1048 & 4412 & 7837 & 953 & 14279 \\
\hline
\end{tabular}

Maximum plasma-concentration $\mathrm{C}_{\max }$

Time to reach maximum plasma-concentration $t_{\max }[\mathrm{h}]$ and Elimination rate constant $\lambda z[1 / \mathrm{h}]$ : could not be determined in any of the volunteers due to non-linear course of the concentration-time profiles.

Area under the plasma-concentration-time-curve AUC(tlast- $\infty$ ): could not be determined, since extrapolation of the concentration-time-curves from last datapoint to inifinite time was not possible in volunteers No. 2,3, 9-13 and 15 due to non-linear run of the curves and was not necessary in volunteers No. 1, 4-8 and 14 because mistletoe lectin serum concentrations had already decreased to or below predose values within the time period of blood sampling, i.e. within the timepoint of last blood sampling (tlast).

${ }^{*} \mathrm{AUC}(0-\infty)$ and apparent subcutaneous clearance $\mathrm{CLsc}(0-\infty)$ : The summary statistics for $\mathrm{AUC}(0-\infty)$ and $\mathrm{CLsc}(0-$ $\infty$ ) included only $n=7$ volunteers, i.e. volunteers No. 1, 4-8 and 14 in whom the total AUC was equal to the AUC(tlast- $\infty$ ). Volunteers No. 2,3, 9-13 and 15 could not be taken into account for the summary statistics of $\operatorname{AUC}(0-\infty)$ and $\operatorname{CLsc}(0-\infty)$, because in these cases AUC(tlast- $\infty$ ) could not be determined (see above).

${ }^{* *} \operatorname{CLsc}(0-72 h)$ and CLsc $(0-336 h)$ : Because the apparent subcutaneous clearance CLsc $(\operatorname{CLsc}(0-\infty))$ could not be determined in most of the volunteers, the apparent subcutaneous clearances for the time periods from 0 to 72 hours $(\mathrm{CLsc}(0-72 \mathrm{~h}))$ and from 0 to 336 hours $(\mathrm{CLsc}(0-336 \mathrm{~h}))$ were determined in all volunteers. 
Table 3: Individual pharmacokinetic parameters of natural mistletoe lectins

\begin{tabular}{|c|c|c|c|c|c|c|c|c|c|c|}
\hline & \multicolumn{10}{|c|}{ 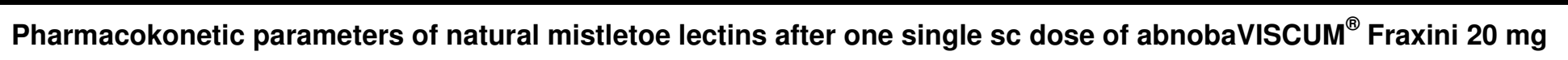 } \\
\hline & \multicolumn{10}{|c|}{ Pharmacokinetic parameters } \\
\hline & $\begin{array}{l}C_{\max } \\
{[p g / m l]}\end{array}$ & $t_{\max }[\mathrm{h}]$ & $\lambda_{z}[1 / h]$ & $\mathbf{t}_{1 / 2}[\mathrm{~h}]$ & $\begin{array}{l}\text { AUC } \\
\left(0-t_{\text {last }}\right) \\
{\left[h^{*} \mathrm{pg} / \mathrm{ml}\right]}\end{array}$ & $\begin{array}{l}\text { AUC } \\
\left(t_{\text {last }} t^{-\infty}\right) \\
{\left[h^{*} \mathrm{pg} / \mathrm{ml}\right]}\end{array}$ & $\begin{array}{l}\text { AUC } \\
(0-\infty) \\
{\left[h^{*} \mathrm{pg} / \mathrm{ml}\right]}\end{array}$ & $\begin{array}{l}\mathrm{CL}_{s c} \\
(0-72 h) \\
{[\mathrm{L} / \mathrm{h}]} \\
\end{array}$ & $\begin{array}{l}\mathrm{CL}_{\text {sc }} \\
(0-336 \mathrm{~h}) \\
{[\mathrm{L} / \mathrm{h}]}\end{array}$ & $\begin{array}{l}\mathrm{CL}_{s c} \\
(0-\infty)[\mathrm{L} / \mathrm{h}]\end{array}$ \\
\hline Volunteer 1 & 715 & 1,0 & * & $*$ & 19083 & \# & 19083 & 3084 & 1048 & 1048 \\
\hline Volunteer 2 & 2970 & 0,7 & * & * & 125405 & $*$ & $*$ & 428 & 159 & $*$ \\
\hline Volunteer 3 & 3738 & 1,0 & $*$ & $*$ & 30141 & $*$ & $*$ & 1719 & 663 & $*$ \\
\hline Volunteer 4 & 2916, & 1,0 & $*$ & $*$ & 3049 & $\#$ & 3049 & 6559 & 6559 & 6559 \\
\hline Volunteer 5 & 593 & 18,0 & * & * & 7161 & 5 & 7161 & 2792 & 2792 & 2792 \\
\hline Volunteer 6 & 660 & 1,0 & $*$ & $*$ & 20984 & $\#$ & 20984 & 2739 & 953 & 953 \\
\hline Volunteer 7 & 1028 & 2,0 & $*$ & $*$ & 4533 & $\#$ & 4533 & 4411 & 4411 & 4411 \\
\hline Volunteer 8 & 959 & 2,0 & $*$ & $*$ & 2552 & $\#$ & 2552 & 7836 & 7836 & 7836 \\
\hline Volunteer 9 & 368 & 10,0 & $*$ & $*$ & 66726 & $*$ & * & 1510 & 299 & $*$ \\
\hline Volunteer 10 & 447 & 2,0 & $*$ & $*$ & 58115 & $*$ & $*$ & 890 & 344 & $*$ \\
\hline Volunteer 11 & 307 & 336,0 & $*$ & $*$ & 85601 & $*$ & $*$ & 1429 & 233, & $*$ \\
\hline Volunteer 12 & 188 & 0,3 & $*$ & $*$ & 39024 & $*$ & $*$ & 2585 & 512 & $*$ \\
\hline Volunteer 13 & 283 & 12,0 & $*$ & * & 18971 & $*$ & $*$ & 4588 & 1054 & $*$ \\
\hline Volunteer 14 & 222 & 1,5 & $*$ & $*$ & 1400 & $\#$ & 1400 & 14279 & 14279 & 14279 \\
\hline Volunteer 15 & 250 & 8,0 & $*$ & $*$ & 37028 & $*$ & $*$ & 2432 & 540 & $*$ \\
\hline
\end{tabular}


Table 4: Safety laboratory parameters: Difference from before to $14 \pm 3$ days after subcutaneous application of $1 \mathrm{ml}$ abnobaVISCUM ${ }^{\circledR}$ Fraxini $20 \mathrm{mg}(n=15)$

\begin{tabular}{|c|c|c|c|c|c|}
\hline Parameter & Lower Quartile & Median & Upper Quartile & $\underset{\mathrm{Cl}}{\text { Lower Limit } 95 \%}$ & $\begin{array}{l}\text { Upper Limit } \\
\mathrm{Cl}\end{array}$ \\
\hline Hemoglobin (g/dl) & -0.9 & -0.2 & 0 & -1.5 & 1.4 \\
\hline White blood count / $\mu \mathrm{l}$ & 70 & 640 & 1220 & -990 & 2680 \\
\hline Platelet count / $\mu \mathrm{l}$ & 58000 & 108000 & 136000 & 3000 & 18000 \\
\hline Creatinine (mg/dl) & 0 & 0 & 0.1 & -0.1 & 0.3 \\
\hline Uric acid (mg/dl) & -0.3 & 0.3 & 0.9 & -1.0 & 1.2 \\
\hline Sodium (mmol/l) & -1 & 1 & 2 & -5 & 3 \\
\hline Potassium (mmol/l) & 0.1 & 0.3 & 0.7 & -0.3 & 1.2 \\
\hline Calcium (mmol/l) & 0 & 0.1 & 0.2 & 0 & 0.3 \\
\hline Creatinkinase (U/I) & -39 & 1 & 19 & -80 & 119 \\
\hline $\begin{array}{l}\text { Alanine aminotransferase } \\
(\mathrm{U} / \mathrm{l})\end{array}$ & 1 & 5 & 20 & -5 & 31 \\
\hline $\begin{array}{l}\text { Aspartate } \\
\text { aminotransferase (U/l) }\end{array}$ & -1 & 2 & 4 & -6 & 11 \\
\hline $\begin{array}{l}\text { Lactate dehydrogenase } \\
(\mathrm{U} / \mathrm{I})\end{array}$ & 11 & 22 & 27 & -10 & 48 \\
\hline $\begin{array}{l}\text { Gamma } \\
\text { gluatmyltransferase (U/I) }\end{array}$ & 0 & 3 & 8 & -2 & 30 \\
\hline Bilirubin (mg/dl) & -0.3 & -0.1 & 0 & -1.3 & 0.4 \\
\hline Alpha amylase $(\mathrm{mg} / \mathrm{dl})$ & -2 & 4 & 11 & -5 & 25 \\
\hline Total protein (g/dl) & 0 & 0.5 & 0.8 & -0.4 & 1.2 \\
\hline Albumin (g/dl) & -0.1 & 0.4 & 0.6 & -0.4 & 0.9 \\
\hline C-reactive protein (mg/dl) & 0 & 0.2 & 0.5 & 0 & 0.7 \\
\hline Cholesterol (mg/dl) & -7 & 2 & 14 & -35 & 32 \\
\hline Triglycerides (mg/dl) & -19 & 5 & 52 & -62 & 103 \\
\hline Glucose (mg/dl) & -3 & -1 & 4 & -4 & 21 \\
\hline
\end{tabular}




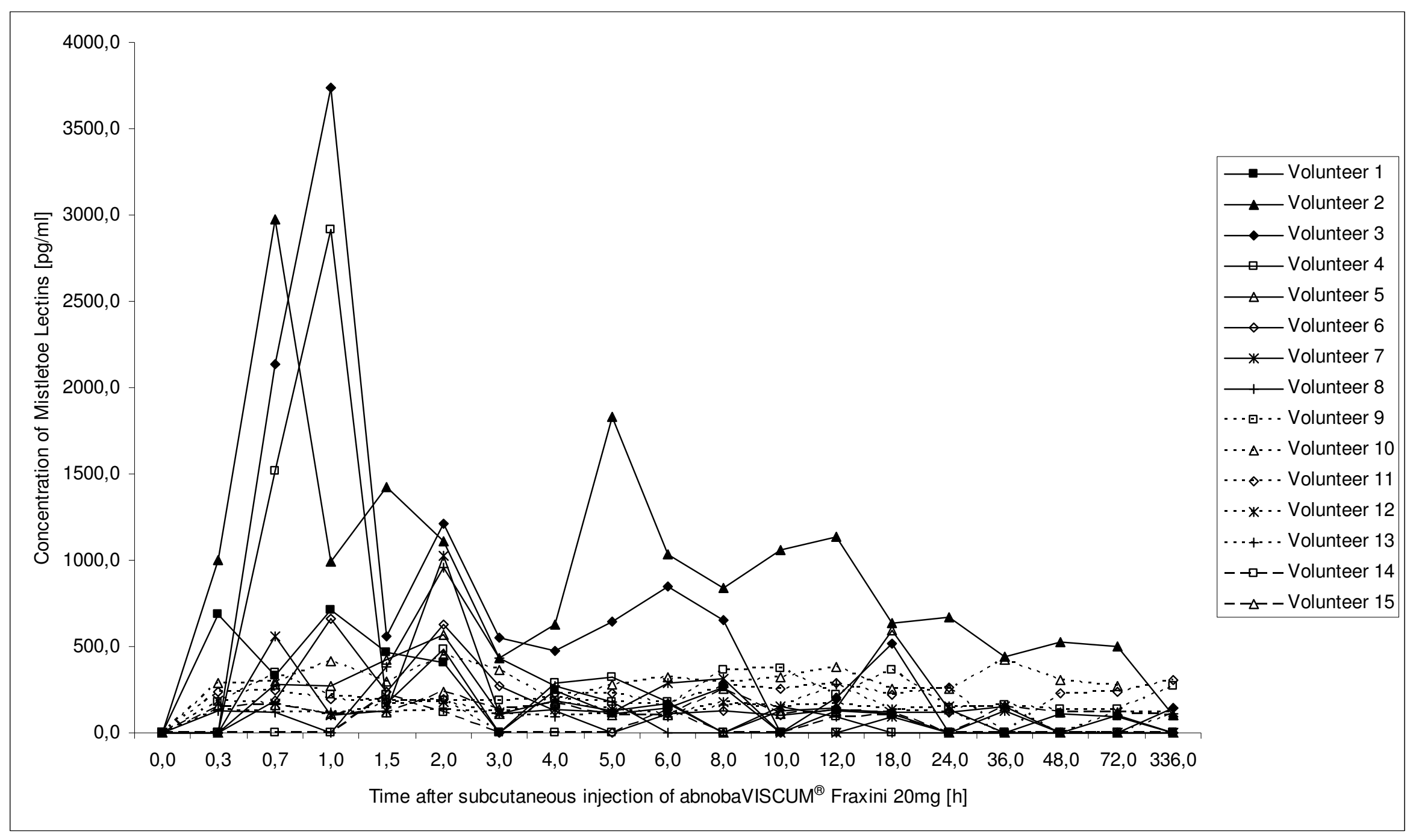

Figure 1: Individual natural mistletoe lectin concentration-time profiles $(n=15)$ 




Figure 2: Arithmetic mean of sublingual body temperature after $(n=15)$ 